\title{
A Mountain-Scale Thermal-Hydrologic Model for Simulating Fluid Flow and Heat Transfer in Unsaturated Fractured Rock
}

\author{
Yu-Shu Wu*, S. Mukhopadhyay, K. Zhang, and G. S. Bodvarsson \\ Earth Sciences Division \\ Lawrence Berkeley National Laboratory \\ 1 Cyclotron Road \\ Berkeley CA 94720 USA
}

\begin{abstract}
A multidimensional, mountain-scale, thermal-hydrologic (TH) numerical model is presented for investigating unsaturated flow behavior in response to decay heat from the radioactive waste repository in the Yucca Mountain unsaturated zone (UZ), Nevada. The model, consisting of both two-dimensional (2-D) and three-dimensional (3-D) representations of the UZ repository system, is based on the current repository design, drift layout, thermal loading scenario, and estimated current and future climate conditions. This mountain-scale TH model evaluates the coupled TH processes related to mountain-scale UZ flow. It also simulates the impact of radioactive waste heat release on the natural hydrogeological system, including heat-driven processes occurring near and far away from the emplacement tunnels or drifts. The model simulations predict thermally perturbed liquid saturation, gas- and liquid-phase fluxes, and water and rock temperature elevations, as well as the changes in water flux driven by evaporation/condensation processes and drainage between drifts. These simulations provide mountain-scale thermally perturbed flow fields for assessing the repository performance under thermal loading conditions.
\end{abstract}

Key Words: thermal-hydrologic processes in subsurface, thermal load, Yucca Mountain, fluid and heat flow in porous media, heat pipe, reservoir simulation, fractured unsaturated rock

\footnotetext{
${ }^{*}$ Corresponding author. Tel.: +1-510-486-7291; fax: +1-510-486-5686, E-Mail address: YSWu@lbl.gov.
} 


\section{Introduction}

In the past decade, the 500-700 m thick Yucca Mountain unsaturated zone (UZ) has been extensively investigated as a potential subsurface repository for storing high-level radioactive wastes. While the site characterization has been mostly carried out for analyzing unsaturated flow and radionuclide transport in ambient, isothermal conditions [30, 31], the inherent nature of nonisothermal flow and transport processes, created by repository heating from radioactive decay, has also motivated many research efforts to understand thermal-hydrologic $(\mathrm{TH})$ behavior and its impact on the repository performance within the UZ. In particular, significant progress has been made in quantitative TH modeling studies at Yucca Mountain [9, 10, 6].

Emplacement of heat-generating high-level radioactive waste in the UZ system of unsaturated welded and unwelded fractured tuff at Yucca Mountain will perturb the ambient condition and create complex multiphase fluid flow and heat-transfer processes. The physical phenomena associated with repository heating include conduction and convection heat transfer, phase change (boiling and condensation), two-phase flow of liquid and gas phases under variably saturated conditions, enhanced fracture-matrix interaction caused by rapid matrix drying and subsequent imbibition, diffusion and dispersion of vapor and gas, and vapor-pressure-lowering effects. These TH processes will last hundreds to thousands of years after waste emplacement, and will significantly redistribute the in-situ moisture content and alter the percolation flux above and below the repository. These processes may particularly affect the water flow or seepage into and around the emplacement drifts, which will have a direct impact on the corrosion rate of waste emplacement canisters, as well as on the potential for transport of radionuclides away from the drifts, carried by the liquid phase into the UZ formation and traveling to the water table.

The need to characterize $\mathrm{TH}$ processes occurring in the UZ geological formation at Yucca Mountain has posed a tremendous challenge for investigators. Because of the large spatial and temporal scales involved in such characterization, quantitative modeling 
evaluation of the coupled fluid-flow and heat-transfer processes has proven to be essential. Quantitative investigation of TH processes at the Yucca Mountain repository site have motivated a continual effort to develop and apply different scale fluid and heat flow models [25, 20, 21, 19, 5, 29, 26, 9, 10, 1, 6, 13, 14, 2]. These numerical models have played a crucial role in understanding coupled fluid and heat flow as well as in assessing how TH conditions affect on various aspects of the overall UZ waste disposal system. Since laboratory studies and field heater experiments, however necessary, are limited in space and time, numerical modeling provides a powerful tool by which to study physical processes on the temporal and spatial scales relevant to understanding nuclear-waste-repository performance in a geological formation.

Despite the significant advances made so far in modeling and understanding $\mathrm{TH}$ processes within the UZ repository system at Yucca Mountain, the previous studies have been (for most part) limited to small spatial- and temporal-scale analysis. For large, mountain-scale multidimensional modeling exercises, the effective continuum model (ECM), rather than the more rigorous DKM (dual-permeability) approach [17], has often been resorted to in these studies [29, 9]. This choice primarily results from the numerical difficulty and computational intensity involved in solving highly nonlinear coupled twophase fluid flow and heat transfer under boiling conditions in unsaturated fractured rock. With the advent of faster computers, mountain-scale TH models implementing the DKM have also been developed [10]. However, the mountain-scale TH model in Haukwa et al. [10] is a two-dimensional model. Mountain scale TH processes have also been investigated with the multi-scale thermal-hydrologic model [6], which also incorporates the DKM approach for fracture-matrix flow. However, the 3-D model consists of integrating fully coupled 2-D TH models at multiple locations in the mountain, in which heat transfer at the mountain-scale occurs only through conduction. In other words, the 3D model [6] does not perform a fully coupled, 3-D TH analyses at the mountain-scale. In general, there has been the lack of modeling effort using the 3-D, mountain-scale, DKM approach for fully coupled TH analyses in Yucca Mountain fractured rock. It is in this context that the 3-D, mountain-scale fully coupled TH model is developed in this paper. 
In the past few years, in parallel to the TH modeling studies, significant progress has also been made in ambient characterization of UZ flow and transport processes. For example, the continual field data collection and modeling studies conducted over the past few years have updated and enhanced our understanding as well as revealed many new insights into how the UZ system works under the natural, ambient conditions [32, 33]. As a result, both UZ geological and conceptual models have been updated by model calibration and verification efforts. In particular, fracture-matrix rock properties and other model parameters have been better estimated and updated. In addition, the repository design and drift layout plans have also been revised, which are different from the ones used in previous TH modeling studies [9, 10]. Since the objective of this paper is to develop a fully coupled mountain-scale TH model that incorporates the-state-of-the-art information about the hydrogeology of the Yucca Mountain site, the above advances in site characterization, data collection, parameter estimates, and repository redesign have been included in developing the TH model in this paper.

This paper presents the results of our continuing effort to develop a representative mountain-scale fully coupled TH model that could characterize TH processes in the UZ repository under thermal load. More specifically, the TH model implements the current geological framework and hydrogeological UZ flow conceptual model, and incorporates the most updated, best-estimated input parameters from the 3-D model calibration [32]. Using the rigorous DKM modeling approach [17], the TH model described in this paper implements a full 3-D representation within the repository and UZ system, which explicitly includes every waste emplacement drift of the repository, in which flow and heat transfer processes along drifts are approximated as porous-medium phenomena without considering the detail of air dynamics within the tunnel. For a better understanding of the ambient geothermal conditions of the UZ system, the TH model is first calibrated against measured borehole temperature data under the ambient geothermal condition. The temperature calibration provides the needed surface and water table boundary, as well as initial conditions for the TH model.

As mentioned earlier, TH perturbation at Yucca Mountain resulting from repository heating has been previously investigated, using a 2-D mountain-scale TH model [10] that 
also implements the contemporary DKM approach for modeling fluid flow and heat transfer in unsaturated fractured rock. However, for investigating TH processes at the mountain-scale, a 3-D TH model is considered more appropriate for various reasons. First, a 2-D representation of TH processes does not account for the differences in rock temperatures at the end of each emplacement drift and at the edges of the repository being different from those at center locations. Second, a 2-D TH model has not accounted for axial flow of vapor and air, a result of natural convection processes and gas pressure differences along the drifts. Such processes can effectively move water vapor from the heated emplacement sections of the drifts to the cooler rock surfaces at the drift ends outside the emplacement sections. Third, 2-D representation does not correctly capture the 3-D behavior of flow in the fractured rock. Because of these reasons, the principal simulations reported on in this paper are performed with a 3-D mountain-scale TH model.

One issue of significant importance in determining the performance of the repository is that of determining the nature of fracture flow between two adjacent emplacement drifts. The nature of fracture flow in that zone will (to an extent) determine whether water will enter emplacement drifts or be diverted through the zone between the drifts. Fracture flow between two adjacent drifts has been investigated at a much smaller scale previously [2], though the change in fracture flow in that region due to mountain-scale alteration in the UZ flow field because of repository heating is an area of active research. The 3-D mountain-scale TH model in this paper, owing to its large spatial extent, has a coarse grid and is therefore not suitable to analyze flow between two emplacement drifts. To investigate this phenomenon, we also perform simulations with a 2-D mountain-scale TH model. The 2-D model grid is a north-south (N-S) vertical cross of the 3-D model, intersecting both repository blocks (see Section 3). The 2-D numerical grid has a refined mesh around the emplacement drifts. The modeling results in this paper are thus obtained from both the 2-D and 3-D mountain-scale TH models.

In this paper, the 2-D and 3-D mountain-scale TH models are employed to predict the TH perturbation at Yucca Mountain. The objective is to investigate spatial and temporal perturbation and its impact on temperature, matrix and fracture liquid saturation, and percolation fluxes in the mountain caused by repository heating. Distribution of 
infiltration fluxes at the top of the mountain and the thermal loading at the repository are the two primary factors that primarily control the evolution of $\mathrm{TH}$ processes in the mountain. Changes in the infiltration flux resulting from climate changes have been accounted for in this paper by considering a time-dependent net infiltration map with a three-step increase, representing present-day, monsoon, and glacial climates (see Section 3). The impact of repository thermal loading on TH processes in the mountain has been investigated in this study by considering two separate thermal loading scenarios with or without ventilation along repository drifts.

This paper is organized as follows. In Section 2, expected mountain-scale TH processes are introduced, along with a brief discussion of the differences between mountain-scale (i.e., at the scale of few tens of meters to hundreds of meters) and drift-scale (i.e., at the scale of few meters to tens of meters) TH processes. Section 3 provides detailed information about the mountain-scale TH models, including the geological model, numerical grid, treatment of fracture-matrix flow, mathematical formulation and numerical code, rock thermal and hydrological properties, and the repository thermal load. Section 4 discusses the ambient infiltration maps and the calibration procedures used to obtain model boundary conditions. The validation and limitation of the mountainscale TH model are discussed in Section 5. Discussion of model results in Section 6 is followed by a summary of the findings in Section 7 .

\section{Mountain-Scale TH Processes}

The TH processes likely to occur in the UZ of Yucca Mountain as a result of heat emanating from the radioactive wastes placed in the emplacement drifts are schematically shown in Figure 1. First, emplacement of heat-generating radioactive waste elevates the temperature of the rock. As heat is continuously transferred from the emplacement drifts to the surrounding rock, temperature approaches or exceeds the boiling point of water (approximately $96^{\circ} \mathrm{C}$ at ambient pressure). Boiling of formation water then takes place, with the associated increase in vapor pressure and overall gas-phase pressure, resulting in forced convection of the gas phase, with a redistribution of water vapor accompanied by large latent heat effects. Water vapor moves into cooler regions of the rock, where it condenses and the liquid water arising out of condensation drains mostly through the fractures under 
gravity. Such two-phase flow of water and vapor often leads to "heat-pipe" conditions, the steady counter-current flow of liquid towards the repository and vapor phase away from the repository. This liquid-phase and gas-phase flow perturbs the in situ fluid saturation and percolation flux in both fractures and matrix, and may result in a large two-phase zone above the repository, as well as an increase in the potential for changes in the flow properties within the condensation zones. The local impact of heat on $\mathrm{TH}$ processes depends mainly on the thermal load and its distribution within repository drifts.

TH processes in the UZ occur at different spatial and temporal scales. During the early part of the heating period, important TH processes occur near the emplacement drifts. TH processes occurring near the emplacement drifts are often termed drift-scale TH ones and have been investigated recently [2]. At the drift-scale, variability in heat output from individual waste packages and different times of waste emplacement may give rise to variability in the extent of dryout, rewetting, and water flux along the drifts. Also at that scale, the availability of additional water in the condensation zone may lead to an augmented fracture liquid flux much greater than the ambient fracture flux, resulting in thermal seepage into the emplacement drifts. This paper does not specifically address seepage under thermal conditions. However, it does analyze the magnitude of percolation flux augmentation caused by long-term heating at the repository. Changes in percolation flux at the mountain scale may influence the potential seepage into drifts during the thermal period.

At later times following waste emplacement, TH processes (i.e., the perturbation in temperature, liquid saturation and percolation flux) take place over a much larger spatial domain (few tens of meters to hundreds of meters) than drift-scale effects (few meters to tens of meters) [10]. These mountain-scale TH processes also include repository edge effects, large-scale enhanced water and gas flow, and temperature elevation in the far field.

\section{Modeling Approach}

Because of the complexity of the UZ geological system, as well as the highly nonlinear nature of the governing equations for UZ flow and transport under thermal loading 
conditions, numerical modeling approaches are used in this work. In particular, the DKM modeling approach [17] has been used in this study for modeling fluid flow and heat transfer processes through the fractured tuffs at Yucca Mountain. This section describes the geological model and modeling approach for handling fracture-matrix interaction, numerical scheme and codes, numerical model grids, input parameters, and repository thermal loads used in the TH model.

\section{Geological Model}

The geological model used for developing the numerical grids for the TH model is based on the current geological framework model [3] for Yucca Mountain. In this geological model, the UZ geological system is organized into layered hydrogeologic units, based primarily on the degree of welding [12]. Table 1 lists the geological units/layers for different hydrogeologic units and the associated $\mathrm{TH}$ model numerical grid-layer information. These major units are the Tiva Canyon welded (TCw) hydrogeologic unit, the Paintbrush nonwelded unit (PTn), the Topopah Spring welded (TSw) unit, the Calico Hills nonwelded unit (CHn), and the Crater Flat undifferentiated (CFu) units.

\section{Numerical Model Grids}

Two numerical model grids are used in this paper, one 2-D and one 3-D grid. The development of 2-D and 3-D numerical grids for the mountain-scale TH model is described in detail elsewhere [32]. The salient features of those numerical grids are summarized here. Numerical grids were generated based on an integral finite-difference scheme [15] with an irregular, unstructured, control-volume spatial discretization. The 3D TH model grid, as shown in Figure 2 in its plan view, covers approximately $20 \mathrm{~km}^{2}$ of the area and uses a refined mesh in the vicinity of the emplacement drifts. The 3-D TH model grid incorporates every repository drift explicitly by taking into account their orientations, lengths, elevations, and spacing. Specifically, a grid spacing of $81 \mathrm{~m}$ is used in the direction perpendicular to drifts, the same as the designed drift spacing. At the repository horizon, a segment of a $5.5 \mathrm{~m}$ diameter cylinder represents waste emplacement drifts for thermal-loading TH studies. 
In the 3-D TH model grid, faults are explicitly represented by vertical or inclined zones of finite width, and properties for gridblocks within the fault zones are adjusted to represent specific fault configurations. The 3-D TH model grid (Figure 2) consists of 86,440 gridblocks, and 343,520 connections between the gridblocks in a DKM mesh.

In addition to the 3-D model grid, the mountain-scale TH model in this paper also uses a 2-D cross-sectional grid, with the plan location (N-S) shown in Figure 2. The 2-D TH model grid, shown in Figure 3, is specifically developed for detailed study of $\mathrm{TH}$ processes with refined grid resolution. The 2-D grid has a total of 39,000 gridblocks and 99,000 connections between the gridblocks in a DKM mesh.

\section{Modeling Fracture-Matrix Interaction}

Modeling fracture and matrix flow as well as their interaction under multiphase and nonisothermal conditions has been a critical issue in simulating fluid and heat flow in the UZ of Yucca Mountain. The available methods for treating fluid and heat flow in fractures and the rock matrix with a numerical approach include: (1) an explicit discrete-fracture and matrix representation; (2) the effective continuum method [9]; and (3) the dualcontinuum method, including double- and multiporosity, DKM, or the more general "multiple interacting continua" method [18]. Different modeling approaches have been tested for handling fracture-matrix interaction at Yucca Mountain [7]. However, the DKM concept has been consistently used as the main modeling approach for simulating flow and transport in the UZ of Yucca Mountain [30], because of its ability to handle flow through both fracture and matrix continua.

The modeling approach used in this work for handling multiphase flow and heat transfer through fractured rock is based primarily on the DKM concept. This approach considers global fluid and heat flow occurring not only between fractures but also between matrix blocks. In this approach, one rock-volume domain is represented by two overlapping (yet interacting) fracture and matrix continua. The fracture-matrix fluid flow is evaluated using the same quasi-steady state approximation as in the double-porosity model [28], which has been extended for estimating local energy exchange terms between fracture and matrix systems [18]. 
Here, the traditional DKM concept is first modified by using an active fracture model [11] to account for fingering effects of fluid flow through fractures. Secondly, the DKM model is used for all formation units and model domains, except for vitric units in the $\mathrm{CHn}$, which are handled as unfractured, single-porosity matrix only. Third, we consider additional global fracture-matrix connections at boundaries of vitric units and at the TCw-PTn and PTn-TSw interfaces, are considered to provide physical transitions for fracture-matrix flow across these units or domain boundaries. Therefore, the modeling approach is actually a physically based, hybrid DKM model, a combination of dualcontinuum and single-porosity medium approximations.

\section{Mathematical Formulation and Numerical Codes}

The physical processes associated with fluid and heat flow in fractured porous media are simulated using TOUGH2 software [22]. Fluid flow and heat-transfer processes in an airwater, two-phase system of fractured rock are described separately using a doublet of governing equations, respectively, for the two fracture and matrix continua. This conceptualization results in a set of partial differential equations for mass and energy conservation in either continuum, which are in the same form as that for a single porous medium. In this work, the multiphase flow system is considered to consist of two phases (gas and liquid) and three components: air, water, and heat. Two-phase flow is described by the multiphase extension of Darcy's law, whereas relative permeability and capillary functions of both fractures and matrix are assumed to follow the model of van Genuchten [27].

In the TOUGH2 family of codes, the effect of molecular diffusion in the water phase is in general ignored. Water and air properties are internally generated, in which air is approximated as an ideal gas and the solubility of air in liquid is described using Henry's law. Heat transfer mechanisms in the two-phase system includes conduction, convection,

and radiation, associated with latent heat caused by phase changes in vaporization (boiling) and condensation in the fractured rock. The integral finite-difference scheme is used for spatial discretization, and time discretization is carried out with a backward, firstorder, finite-difference scheme. The resulting discrete nonlinear algebraic equations for 
describing mass and energy conservation are written in a residual form, and solved using the Newton/Raphson iteration scheme.

\section{Rock and Thermal Parameters and Their Specification}

Rock and fluid-flow parameters were estimated in several studies [32, 8, 16] for modeling UZ flow. In addition, thermal properties, including grain density, wet and dry thermal conductivity, and grain-specific heat for each model grid layer, are provided in Wu et al. [32]. Temperature-dependent fluid properties, such as fluid density, viscosity, and specific enthalpy, are incorporated in the formulation of the TOUGH2 code.

The rock and thermal parameter specifications in the TH model are, in general, layerwised. However, certain portions of the $\mathrm{CHn}$ stratigraphic unit are partly altered from vitric to zeolitic. In these altered layers, different rock properties are specified according to vitric or zeolitic zones. All the geological units of Table 1, including those representing fault zones, are treated as fracture-matrix systems using a DKM approach-except the $\mathrm{CHn}$ vitric zones, which are treated as a single-continuum matrix, because flow within these units is matrix dominated (and units exhibit sparse fracturing).

\section{Repository Thermal Load}

The average thermal line load of $1.45 \mathrm{~kW} / \mathrm{m}$, designed along each emplacement drift, is used to impose the radioactive heat source. The time-dependent thermal decay is shown in Figure 4. The value of $1.45 \mathrm{~kW} / \mathrm{m}$ refers to the initial thermal line load that decreases with time as a result of radioactive decay. A sensitivity study was also carried out in which heat was removal by forced ventilation. In this "ventilation" model, during the first 50 years after waste emplacement, $86.3 \%$ of the heat is assumed to be removed by ventilation (see Figure 4). After the first 50 years, the full thermal load becomes applicable (i.e., no difference in thermal load with the no-ventilation case). Note that the actual process of ventilation was not modeled in this paper, though the heat-generation rate was reduced to account for heat removal by ventilation. 


\section{Calibration for Estimating Boundary and Initial Conditions}

As the first step in developing the mountain-scale TH model, an ambient TH model (i.e., heat from radioactive waste is not included) is developed for estimating the ambient geothermal gradients, as well as boundary and initial conditions for thermal loading simulations. For this model, fluid and heat flow is simulated using the 3-D TH model grid (Figure 2), the calibrated UZ model parameters [32], and present-day infiltration rate (see below). This ambient TH model is then calibrated using the measured temperature data from many boreholes at the site, as discussed in this section.

\section{Model Boundary Conditions}

Both 2-D and 3-D mountain-scale TH models use the ground surface of Yucca Mountain (or the tuff-alluvium contact in areas of significant alluvial cover) as the top model boundary. The water table is treated as the bottom model boundary. Both the top and bottom boundaries of the models are treated as Dirichlet-type conditions with specified constant with time, but spatially varying temperatures and gas pressures.

All lateral boundaries, as shown in Figure 2, are treated as no-flow (closed) boundaries, which allow flow only along the vertical plane. The water table, which is the bottom boundary of the mountain-scale TH model, is shown to be a relatively flat, stable surface over most of the model domain, increasing its elevation only in the north. For most areas in the middle and southern part of the model domain, the flat portion of the water table is about $730 \mathrm{~m}$ above sea level (masl). Gas pressures are estimated as $92 \mathrm{kPa}$ at an elevation of 730 masl. Surface gas pressures are determined by running the TOUGH2 software to steady-state under given temperature, bottom pressure, and surface-infiltration conditions. This treatment is necessary to generate a steady-state, equilibrated gaspressure boundary to avoid artificial airflow or circulation, which may occur if nonequilibrated pressures are imposed on the ground surface and bottom boundaries.

\section{Top Boundary Temperature Condition}

To account for variations in atmospheric temperature with surface elevations in the mountain, measured mean surface temperatures are correlated to elevation using a linear 
equation. The annual average surface temperature at Yucca Mountain was measured continuously for several years. Surface temperatures $T_{s}$ at any elevation $Z$ are then computed as constants, according to the following equation [30]:

$$
\mathrm{T}_{\mathrm{s}}=\mathrm{T}_{\mathrm{ref}}-\lambda\left[\mathrm{Z}-\mathrm{Z}_{\mathrm{ref}}\right]
$$

where $T_{\text {ref }}$ is mean surface temperature at reference elevation $Z_{\text {ref }}$ and $\lambda$ is the dry adiabatic atmospheric lapse rate in ${ }^{\circ} \mathrm{C} / \mathrm{m}$. This lapse is approximated at $0.01^{\circ} \mathrm{C} / \mathrm{m}$, based on the borehole temperature measurements. The surface reference temperature $T_{\text {ref }}$ is estimated at $18.23^{\circ} \mathrm{C}$ with the measured surface temperature data at an elevation of $\mathrm{Z}_{\mathrm{ref}}=$ 1,231 m.

\section{Bottom-Boundary Temperature Condition}

The initial estimates of temperature distributions at the bottom boundary, the water table, of the TH model, are estimated by contouring the temperature data, measured from 25 boreholes at an elevation of 730 masl [24, 23]. Because the water table is not completely flat in the current UZ and TH models (See Figure 3), the actual estimates of the water table or bottom-model-boundary temperatures are made by interpolating the temperature values at 730 masl elevation and along the model surface boundary. Then, initially estimated ground surface and water table temperatures are further calibrated by comparing model results with field temperature measurements.

\section{Surface Infiltration}

Water entering the UZ as net infiltration from precipitation at the land surface is the ultimate source of percolation within the UZ at Yucca Mountain, and to a large extent controls the evolution of hydrological and $\mathrm{TH}$ conditions in the mountain. Water percolating downward through the UZ is the principal medium by which radionuclides may be transported from the repository to the water table. Such percolation could also have a direct impact on the evolution of TH processes near the waste emplacement drifts.

While only the present-day infiltration map is used for calibration of the ambient $\mathrm{TH}$ model, the mountain-scale TH model uses three net infiltration rates as surface-water- 
recharge boundary conditions. The three net infiltration rates consist of one present-day and two future (monsoon and glacial infiltration, respectively) scenarios, determined by studies of modern and future climates [4]. A plan view of the spatial distribution for the present-day infiltration map, as interpolated into the 3-D UZ TH model grid, is shown in Figure 5. The figure shows a pattern of flux distributions for the present infiltration, with higher infiltration rates in the northern part of the model domain and along the mountain ridge east of the Solitario Canyon fault.

The actual timing and the averages of the TH-model three infiltration rates are shown in Table 2, indicating average values over the model domain for three time periods. Table 2 shows that the mountain-scale TH model implements three infiltration rates over three time periods for the thermal-loading investigation. The future climates are considered to act sequentially over the modeled period: present (0 to 600 years), monsoon (600 to 2,000 years), and then glacial transition (2,000 years and beyond). As shown in Table 2, the average rate over the model domain for present-day infiltration is $3.6 \mathrm{~mm} / \mathrm{yr}$.

\section{Calibration of Ambient Temperatures}

The temperature profiles or geothermal gradients within the UZ system are controlled by several factors, such as formation thermal conductivity and net infiltration rates, in addition to the regional geothermal and weather conditions. Measured thermal conductivities are relatively accurate for the different geological units, but temperature calibration may be conducted using either ambient infiltration or model boundary temperatures, or both. In this work, the ambient net infiltration rate is fixed as the present-day infiltration rate, with a value of $3.6 \mathrm{~mm} / \mathrm{yr}$ within the grid domain (Figure 5). Temperatures are slightly adjusted from the estimated values along the top boundary only, and this adjustment results in a better match of observed borehole data. There are several reasons for this adjustment. First, insufficient temperature data was collected along these boundaries for accurate description of temperature distributions. Second, under steady-state moisture and heat-flow conditions, both top and bottom boundary temperatures are spatially varying constants, which leaves room for adjusting to fit measured steady-state temperature profiles from boreholes. Then the simulations are all run to steady state for comparison with measured borehole temperatures. 
During calibration, the corresponding simulated borehole temperature profiles are extracted from the model output and then plotted against the measurements along each borehole. Figure 6 shows the final model calibrated results and measured temperature profiles in the six temperature boreholes. The figure displays a good match between measured and simulated temperatures for all six boreholes. Note that near the ground surface in the boreholes, observed temperatures show significant seasonal variations. However, these seasonal changes in surface temperature have little impact on steady-state heat flow or temperature profiles in the deeper (more than $20 \mathrm{~m}$ ) UZ. This also indicates that the ambient geothermal conditions can be approximated as steady state on the large spatial and temporal scale model.

\section{Model Verification and Limitations}

The verification effort of the mountain-scale TH model has been dealt with elsewhere [34]; the key features of the model verification activities are summarized here. Because of the large spatial and temporal scales of the mountain-scale $\mathrm{TH}$ models, model validation through direct comparison with measured $\mathrm{TH}$ data from any field test is not possible: designing such a test is not feasible. The physical processes modeled by the mountain-scale TH model has also been modeled by the Drift-Sscale TH Model [2], although over a smaller (space and time) scale. The drift-scale TH model uses the same conceptual and mathematical models for representing the same physical processes as those with the mountain-scale TH models in addition to the same numerical simulator. Results from the drift-scale TH model have been examined against measured temperature and saturation data from the Drift-Scale Test (DST). The DST is the largest of the three thermal field tests performed at Yucca Mountain [2]. The heating phase in the DST lasted slightly more than four years, and a large volume of rock was heated to temperatures close to and above boiling. Considerable high-quality TH data were collected from the DST. These data gave an adequate representation of the $\mathrm{TH}$ processes likely to be encountered in the near-field of the emplacement drifts. Through a detailed comparison of measured and simulated TH data, it was concluded that TH processes were adequately represented by the drift-scale TH model [2]. This finding corroborates the mountain-scale 
TH model, because the underlying thermal and hydrologic transport processes are identical.

The accuracy and reliability of the mountain-scale TH models and their predictions are critically dependent on the accuracy of estimated model properties, other types of input data, and hydrogeological conceptual models. These models are limited mainly by the current understanding of the mountain system, as developed from geological and conceptual models, the volume-average numerical modeling approach, and the available field and laboratory data. By definition, models are idealizations of the real world. The mountain-scale TH models are continuum models, using averaged properties, and therefore are meant to represent overall changes in space and time. Input data characterize the physical properties of the rock, but cannot include every detail of a natural system. As a result of such simplifications, the model results must be applied with caution when predicting future conditions at any specific location.

\section{Results and Discussion}

In analyzing the expected TH changes in the Yucca Mountain unsaturated fractured rock resulting from repository heating, the important issues are: (1) How far (laterally and vertically) is the impact of heat likely to spread? How long will it take for temperatures in the mountain to return to pre-emplacement ambient conditions? (2) To what (spatial and temporal) extent is water redistributed caused by repository heating either in the rock matrix or fractures? (3) How is repository heating going to alter (if at all) the percolation flux distribution in the mountain? Obtaining reliable information about these thermal (temperature) and hydrological (water redistribution in the matrix and the fractures, and percolation flux distribution) are essential for correctly predicting the performance of the repository. In the following, results are presented from both the 3-D and 2-D mountainscale $\mathrm{TH}$ models to provide predictive information about those $\mathrm{TH}$ changes. The first set of results presented here is obtained with the mountain-scale $\mathrm{TH}$ models, in which no repository heat is removed by forced ventilation (see Figure 4). Heat removal by forced ventilation will have some impact on the expected mountain-scale TH processes. The impact of ventilation on mountain-scale $\mathrm{TH}$ processes is demonstrated here by 
simulations with the mountain-scale TH models, in which about $86 \%$ of repository heat is removed by ventilation during the first 50 years after waste emplacement (see Figure 6 for the thermal loading scenario under these circumstances).

\section{Temperature}

Figure 7 shows contours of temperatures in a horizontal cross section at the repository horizon of the 3-D numerical grid. After waste emplacement, temperatures start to increase rapidly near the emplacement drifts, and rock temperatures are expected to exceed boiling temperatures within 2-10 years at the repository horizon. Around 100 years, a portion of the rock at the repository horizon is above boiling (Figure 7a). Peak rock temperatures are predicted to be $120-140^{\circ} \mathrm{C}$ around this time. Since repository heating declines with continuous radioactive decay, rock temperatures start to decline afterwards. At 500 years, temperatures at the repository horizon have declined below boiling, though the rock is still very hot at that location (Figure 7b). Over time, temperatures decline further and are expected to be no more than $55^{\circ} \mathrm{C}$ at the repository horizon at 5,000 years (Figure 7c). Though not shown here, temperatures at the repository horizon return near ambient conditions before 10,000 years. Note also that the northern part of the repository is expected to be warmer than the southern part (Figures $7 \mathrm{a}$ and $7 \mathrm{~b}$ ) even though the ambient percolation fluxes are considerably higher in the former. This is because the concentration of emplacement drifts is greater in the northern part of the repository (see Figure 2) and thus the thermal load is much larger.

The expected lateral and vertical extent of temperature perturbation in the mountain is presented in Figure 8, where contours of temperature are shown in a N-S vertical cross section of the 3-D numerical grid (this cross section is approximately at the same location as the 2-D numerical grid shown in Figure 3). Figure 8 shows the temperature distribution at 500 (Figure 8a), 1,000 (Figure 8b), and 5,000 years (Figure 8c). Vertically, temperature perturbation is expected to spread about 200-250 m above and below the drift. Laterally, there is no indication that temperature will be perturbed at all beyond $100-150 \mathrm{~m}$ from the last emplacement drift. Note that there appears some discontinuity in temperature contours at the southern end of the repository blocks along ,the cross section 
(figures 8a and 8b). Actually this is caused by coarse-grid effects where temperatures plotted from two meshes which are not directly connected and therefore there is the lack of smooth transition. Note also that there is the some small-scale heterogeneity in the lateral temperature perturbation field apart from the difference in temperature perturbation between the northern and southern parts of the repository (as explained in the paragraph above). The small-scale heterogeneity in the predicted lateral temperature distribution results from differences in spatial percolation flux distribution.

The impact of repository heating on temperature perturbation in the mountain is shown more quantitatively in Figure 9. While Figures 7 and 8 are extracted from the 3-D mountain-scale TH model results, Figure 9 is produced with the 2-D mountain-scale TH model. Figure 9a shows the expected peak rock temperatures at various times along the $\mathrm{N}-\mathrm{S}$ axis of the 2-D numerical grid (see Figure 3). Temperatures in the drift vicinity (the first rock element above the emplacement drifts) are in the $120-140^{\circ} \mathrm{C}$ range at 100 years; however, the rock between two adjacent drifts (hereafter referred to as the "mid-pillar") is at a considerably lower temperature. The mid-pillar actually never exceeds boiling temperature, which allows percolation fluxes to drain through this area. (This will be discussed further in the context of fracture saturation distribution.) At later times, temperature decreases with decrease in repository heating (see Figure 4). Observe that over time, the difference in temperature between the mid-pillar and the drift vicinity diminishes, and the "spikes" in the temperature gradually disappear. By 5,000 years, temperatures are expected to be around $55^{\circ} \mathrm{C}$ only. Observe that temperatures in the northern part of the repository are declining faster than in the southern part, even though the former reached a higher peak temperature than the latter. This is because the percolation fluxes are larger in the northern part than in the southern part.

The emplacement drifts at Yucca Mountain are to be located in the middle nonlithophysal and lower lithophysal units of the Topopah Spring Tuff (TSw). (See Table 1 for a description of the various geological units.) To examine the vertical extent of temperature perturbation at the mountain, temperatures at the bottom of the PTn stratigraphic unit, located about 100-125 m above the emplacement drifts, are shown at various times in Figure $9 \mathrm{~b}$. While the rock temperatures are significantly above boiling at the repository 
horizon around 100 years, no visible perturbation in temperature appears at the bottom of the PTn at that time. Peak temperatures at the bottom of the PTn unit are reached around 1,000 years, after which they begin to decline, barely exceeding $60^{\circ} \mathrm{C}$ and returning to around $30^{\circ} \mathrm{C}$ by 8,000 years. Thus, temperature perturbation is never more than $40^{\circ} \mathrm{C}$ above ambient conditions at the bottom of the PTn. Therefore, no boiling conditions are expected at this location. Similar trends are observed below the repository, as illustrated in Figure 9c, which shows the temperatures at the top of the CHn stratigraphic unit (see Table 1), located about $75-100 \mathrm{~m}$ below the emplacement drifts. Figure 9c is similar to Figure 9b, except that the peak temperatures are somewhat higher at the top of the $\mathrm{CHn}$ unit compared to that at the bottom of the PTn unit. This is because the $\mathrm{CHn}$ unit is located closer to the repository horizon. In short, boiling temperatures are not expected anywhere in the repository rock, except in the immediate vicinity of the emplacement drifts.

The signature of boiling and subsequent condensation, which results from the creation of a two-phase zone, is the heat-pipe (i.e., a zone of constant temperature over space or time) in a temperature plot. As an example, Figure 9d shows the distribution of temperature along a vertical column from the ground surface at the top to the groundwater table at the bottom. This column is located near the center of the repository with Nevada coordinates $170630 \mathrm{~m}$ (E-W) and $234103 \mathrm{~m}$ (N-S). The emplacement drift is located around 1063 masl in this column. Temperature gradually increases from ground surface till it reaches the location of the drift, and then it declines thereafter towards the water table. This is true at all times, except between 100-1,000 years, when there is a heat-pipe just above the emplacement drift, where the temperature is constant. This zone of constant temperature signifies the presence of a two-phase condition. The two-phase zone is predicted to be lying about 10-20 m above the emplacement drift. It can be concluded that boiling is limited within a radius of that extent around each emplacement drift. A more refined grid is needed to get an accurate location of the boiling zone. 


\section{Matrix Liquid Saturation}

Boiling of water leads to redistribution of moisture in the rock matrix. As Figure 9d indicated, boiling takes places in the immediate vicinity of the emplacement drift, after which the vapor condenses in cooler parts of the rock. As a result, significant drying takes place in the matrix around the emplacement drifts. However, since no boiling takes place in the mid-pillar, no significant drying is expected in the zone between two adjacent drifts. Thus, if matrix liquid saturation is plotted along the N-S axis of the repository, a widely fluctuating pattern is expected immediately after waste emplacement (since boiling takes place at early times). This is shown in Figure 10a, where the rapidly fluctuating pattern of matrix liquid saturation is seen at 100 years. At later times, as boiling ceases and more percolation fluxes become available due to climate changes, significant rewetting occurs because of capillary suction of the matrix pores in the previous dryout zones. This rewinding results in a relatively smoother distribution of matrix saturation at later times.

Since boiling is not expected to occur except in the immediate vicinity of the emplacement drifts, only limited change occurs in matrix saturation with time at other locations in the mountain. This is confirmed in Figures $10 \mathrm{~b}$ and $10 \mathrm{c}$, where the matrix liquid saturation along the N-S axis is shown for various times at the bottom of the PTn unit and the top of the $\mathrm{CHn}$ unit, respectively. At both locations, limited drying is observed between 100 and 500 years. Thereafter, matrix saturation increases because of the additional water becoming available as a result of climate change. The significantly higher matrix saturation at the northern part of the repository in Figure 10c is due to vitric-zeolitic transition. Limited changes in matrix saturation in the mountain with time are also illustrated in Figure 10d, where matrix saturation along a vertical column (the same column as in Figure 9d) is shown at various times. Drying is prominent only around the drift. Elsewhere, matrix saturation changes little from ambient condition, the minor changes attributable to an increase in percolation fluxes at later times owing to climate change. 


\section{Fracture Liquid Saturation}

In the unsaturated fracture rock of Yucca Mountain, flow in the rock matrix and fractures occurs at a different scale. Flow in the porous rock matrix is slow (permeability is a few orders of magnitude smaller than that of the fractures), and the matrix mostly provides storage for water because of its higher capillarity and larger pore volume. The fractures, on the other hand, have very little storage capillarity, and flow through them is relatively fast. Under ambient conditions, therefore, the fractures at Yucca Mountain are relatively dry (compared to the rock matrix) and fracture saturations are of the order of $1-2 \%$ at the repository horizon. Repository heating causes the fractures to be absolutely dry near the emplacement drifts (see Figure 11a), creating a dryout zone. On the other hand, since water displaced from the matrix pores by boiling flows mostly through the fractures, fracture saturation increases elsewhere, particularly in the condensate zone situated outside the dryout zone. However, the increase in fracture saturation is limited at the spatial scale is of interest in this paper. Once the boiling period is over, fracture saturation increases marginally because of larger percolation fluxes caused by climate change. The same pattern is observed in Figures $11 \mathrm{~b}$ and 11c, where fracture saturations at the bottom of the PTn and the top of the CHn, respectively, are shown at different times. It is clear that changes in fracture saturation in the mountain are small in magnitude. The vertical

profile of fracture saturation is shown in Figure 11d. The first spike in Figure 11d represents the buildup in fracture saturation just above the emplacement drifts because of the capillary barrier effects of an open cavity (i.e., the emplacement drifts). The second spike at around $925 \mathrm{~m}$ is a model artifact, as the vitric-zeolitic transition zone is modeled as matrix only.

\section{Percolation Flux}

One of the primary utilities of the mountain-scale TH model is to analyze the impact of repository heating on the spatial distribution of percolation fluxes. The ambient vertical fracture fluxes in a horizontal cross section at the repository horizon of the 3-D numerical grid are shown in Figure 12a. The ambient percolation flux distribution is generated using the present-day infiltration scenario (see Table 2). Observe that the south-east part of the 
repository is drier compared to other locations. In the central part of the repository (to the left of the Drillhole Wash Fault), the percolation fluxes in the fractures are of the order of 7-9 mm/year under ambient conditions. Compare Figure 12a with Figure 12b, which shows the distribution of vertical fracture fluxes at 500 years in the same cross section as that of Figure 12a. Percolation fluxes significantly increase in the repository horizon, particularly in the areas directly above the drifts. Again, water displaced from the rock matrix by boiling condenses above the dryout zone and drains through the fractures. As a result, percolation fluxes in the fractures above the drift increase considerably during and immediately after the boiling periods.

The nature of fracture percolation flux distribution under repository heating is more clearly seen in Figure 12c, which shows the vertical fracture fluxes in a vertical column extending from the ground surface to the water table. The ambient fracture flux at the ground surface at this location is about $9 \mathrm{~mm}$ /year. Above the repository (in the condensate zone), however, the vertical fracture fluxes are expected to exceed 50 $\mathrm{mm} /$ year at 100 years, resulting from displacement of matrix pore water by boiling. At the same time (i.e., 100 years), fracture fluxes just below the repository are considerably smaller. Because of the capillary barrier effects of the emplacement drifts, water cannot enter the drifts and is diverted through the pillar region, resulting in a relatively dry region below the drift. This dry region is often termed the "shadow zone." Over time, boiling ceases and the fracture flux distribution becomes similar above and below the drifts. The increase in fracture fluxes at later times is attributed to increase in percolation flux due to climate change.

Drainage through fractures is illustrated in Figure 12d. This figure shows the magnitude of vertical liquid flux in fractures along the N-S axis just above the repository. Figure 12d also shows the surface infiltration maps along the N-S axis for present-day, monsoon, and glacial transition periods by bold lines. Fracture fluxes appear to be elevated in the mid pillar regions. As further clarified in Figure 12e, where a close up of the vertical fracture fluxes in the pillar regions is shown. Though a more refined numerical grid would have provided a clearer picture of drainage through pillars, Figure 12e is sufficiently informative. First, no fracture liquid fluxes are observed directly above the emplacement 
drifts. Because of drying (thermal barrier) and capillarity (capillary barrier) effects, water is diverted away from locations just above the emplacement drifts, resulting in elevated fluxes in the pillar region.

\section{Impact of Ventilation}

The results presented so far have all been obtained from the mountain-scale TH model where there was no heat removal by ventilation. The extent of thermal and hydrological perturbation in the mountain, however, may be altered if the thermal loading is different. One way to modify the thermal loading at the repository is to remove part of the heat by ventilation. A sensitivity study was therefore carried out to investigate the impact of ventilation on the extent and duration of the thermal perturbation in the mountain. In this sensitivity study, $86.3 \%$ of the heat was removed by ventilation during the first 50 years after emplacement (see Figure 3). In the following, important $\mathrm{TH}$ results from the sensitivity study are presented and compared with TH changes in the mountain when there is no heat removal by ventilation.

Figure 13a shows the temperature from the ventilation scenario along the N-S axis just above the repository horizon. This figure should be compared with Figure 9a, which shows temperature at the same location from the no-ventilation scenario. While the patterns of temperature rise and decline are similar for both the cases, the peak temperatures for the ventilation case are significantly smaller than those in Figure 9a. Although the difference in temperature between the no-ventilation and ventilation case is substantial during the initial phases of heating, the difference decreases as heat load decreases with time. At 8,000 years, the base case and no-ventilation case are almost indistinguishable as far as temperature is concerned.

Figures 13b shows the thermal perturbation at the bottom of the PTn when heat is removed by ventilation. Recall that when there is no ventilation (Figure 9b), the temperature at the bottom of the PTn reached a maximum of about $65^{\circ} \mathrm{C}$ at 1,000 years. When ventilation is introduced, a peak temperature of approximately $50^{\circ} \mathrm{C}$ is realized at the bottom of the PTn. However, this peak is reached later (at 2,000 years) compared to the no-ventilation case. With no ventilation, boiling takes place around the emplacement 
drifts. Thus, heat transfer occurs both through conduction and convection, and heat reaches the bottom of the PTn quickly. When the imposed thermal load is smaller (i.e., when ventilation is present), no significant boiling takes place and heat transfer through the rock is predominantly by conduction. Hence, in this case the transfer of heat through the rock is slower, and the peak temperature at the bottom of the PTn is reached later in this case. Over time, the difference in temperatures from the two thermal-loading scenarios continues to decrease, and at 8,000 years, no noticeable difference appears in the temperatures predicted by these two scenarios. One inference from this is that the impact of heat loading is the largest close to the repository (drift-scale), and the maximum impact is limited to the first 1,000 years or so elsewhere in the mountain. This is further demonstrated in Figure 13c, where temperature along a vertical column is shown at various times. When compared to Figure 9d, Figure 13c shows a difference of about $40^{\circ} \mathrm{C}$ in temperature at the repository horizon at 100 years with the two thermal loading scenarios. Also, since no boiling occurs during ventilation, the heat-pipe signature is absent in Figure 13c (see Figure 9d for a comparison). Over time, the difference in temperature at any given location between the two thermal loading scenarios decreases and is no more than $2-5^{\circ} \mathrm{C}$ by 8,000 years. This again illustrates that the effect of ventilation is important only during the first few thousand years, and there too the impact is most observable close to the emplacement drifts.

The absence of large-scale boiling in the simulations with ventilation means that no significant moisture redistribution in the matrix should be expected. This is demonstrated by showing the matrix saturation along the N-S axis for these simulations in Figure 14, which should be compared with Figure 10a. Matrix saturation along a vertical column also shows minor moisture redistribution in the matrix (Figure 15) as compared to the noventilation simulations (Figure 10c). Though not shown here, fracture saturations also exhibit no significant change in the simulations with ventilation.

As shown in Figure 16, the most important impact of ventilation is on the distribution of fracture percolation fluxes. This figure shows vertical liquid fluxes in the fractures for the two thermal-loading scenarios at 100 years and 500 years (the peak thermal perturbation times) just above the repository. In this figure, the solid lines refer to the "ventilation" 
thermal-loading scenario, and the dotted lines correspond to the no-ventilation thermalloading scenario. Vertical fluxes are not shown along the entire N-S axis of the repository but over a distance covering a few typical emplacement drifts. The figure shows detailed evolution of fracture fluxes in the pillar regions between adjacent drifts. Observe that, both at 100 years and 500 years, the vertical fracture fluxes in the pillar region for the noventilation case are twice as large as those for the ventilation case, because more water is displaced by boiling in the no-ventilation case than in the ventilation case. Additionally, because of higher temperatures and more extensive boiling in the no-ventilation case, the thermal barrier is larger both in spatial and temporal extent compared to the ventilation. This difference results in a larger diversion of water through the pillar region for the noventilation case, and also indicates that, even during peak thermal perturbation (resulting from the higher heat load in the no-ventilation case), drainage takes place through the pillar region. Fracture fluxes just above the repository arising out of the two thermalloading scenarios are similar once the thermal regime ends (i.e., after about 5,000 years).

\section{Summary and Conclusions}

This paper describes the development of a mountain-scale TH model and its application to assess thermal and hydrological changes and predict UZ flow behavior in response to repository heat release at Yucca Mountain. The TH model numerically simulates the impact of nuclear-waste heat release on the natural hydrogeological system, including a representation of heat-driven processes occurring at the repository drifts as well as in the far field. The mountain-scale TH model provides predictions for thermally affected liquid saturation, gas- and liquid-phase fluxes, and water and rock temperature. In particular, the TH model calculates the changes in water flux driven by evaporation/condensation and capillary processes, and drainage occurring between drifts.

The mountain-scale TH model in this paper consists of one 2-D and one 3-D submodel, both of which use the dual-permeability modeling approach. The 3-D TH model grid, though having relatively coarse grid spacing, incorporates every repository drift explicitly by taking into account orientations, lengths, elevations, and spacing of the repository drifts, such that adjacent drifts are represented one-to-one by adjacent gridblocks $81 \mathrm{~m}$ 
wide. In comparison, the 2-D model employs very refined lateral and vertical grids with an explicit drift representation along the north-south cross section. To account for future climates and their impact on TH behavior at the repository, the mountain-scale TH model implements three infiltration rates over three time periods, stepped up sequentially over the modeled period: present-day (0-600 years), monsoon (600-2,000 years), and glacial transition (2,000 and beyond). Initial and boundary conditions are obtained by calibration to observed geothermal gradients at Yucca Mountain. Representative repository thermal load at Yucca Mountain is used as the source of heating. Two thermal loading scenarios are investigated. In the first scenario, no heat is removed by ventilation. In the second scenario, approximately $86 \%$ of the repository thermal load is removed by forced ventilation during the first 50 years after waste emplacement.

Without heat removal by ventilation, mountain-scale TH model results show that significant boiling takes place in the vicinity of the repository drifts. However, the zone of above boiling temperature is restricted within approximately $10 \mathrm{~m}$ around the drifts. The mid-pillar is not expected to reach boiling temperature. It is also observed that temperature perturbation is expected to extend about $200 \mathrm{~m}$ above and below the drifts. Laterally, no temperature perturbation is observed more than $150 \mathrm{~m}$ away from the last emplacement drift. Temperatures in the mountain are expected to return to preemplacement conditions well before 10,000 years. Boiling around the emplacement drifts causes significant drying in matrix at those locations. Outside the drying zone, there exists a small zone of increased matrix saturation caused by condensation of displaced pore water by boiling. At larger distances from the drifts, virtually no change in matrix saturation occurs due to repository thermal load. At late times, matrix saturation increases, due to rewetting from increased percolations fluxes arising from climate change. The fractures at Yucca Mountain are extremely dry under ambient conditions. During the thermal period at Yucca Mountain, water displaced by boiling drains through the fractures. Such drainage causes the fracture percolation fluxes to increase by a factor of 2 to 5 from their ambient values. However, most of the drainage happens through the mid-pillar, because the capillary barrier effects surrounding repository drifts do not permit water to enter them. Also, the above-boiling dryout zone around the drifts causes 
infiltrating water to evaporate during the thermal period, thus further reducing the possibility of water flowing into the drifts.

Mountain-scale TH model results demonstrate that, when heat is removed by ventilation, rock temperatures around the drift barely reaches boiling (temperatures within the drifts though may be above boiling). Since no significant boiling takes place in this thermal loading scenario, changes in matrix and fracture liquid saturation due to repository heating is limited. The enhancement in fracture percolation fluxes during the thermal period is also significantly smaller compared to the no-ventilation thermal loading scenario. Overall, the impact of ventilation on the evolution of TH processes at Yucca Mountain is limited in the vicinity of the drifts and during the first few hundred years or so. Elsewhere in the mountain and at other times, the TH conditions are comparable between the two thermal loading scenarios.

The mountain-scale TH models in this paper provide a contemporary understanding of the TH processes likely to occur in the mountain. These models not only provide useful predictions about the $\mathrm{TH}$ conditions in the mountain, but also provide the model results for safe design of the repository. As a result, reliability of these models is an important issue. Verification efforts for the mountain-scale TH models have been discussed in Section 5, where it can be concluded the model results are as reliable as the input parameters to the model. There are, of course, certain limitations to the mountain-scale models, which have also been discussed in Section 5. One significant limitation to the mountain-scale TH model in this paper is that it does not incorporate small- and largescale heterogeneities within each stratigraphic units. In addition, repository heating causes chemical and mechanical changes in the rock. These chemical and mechanical changes in turn alter the hydrological properties of the rock, which have the potential to alter the $\mathrm{TH}$ response of the rock. These dynamic changes in the rock concurrent with repository heating have not been considered in this paper. Future modeling efforts may be directed towards resolving some of these issues. 


\section{Acknowledgments}

This work was supported by the Director, Office of Civilian Radioactive Waste Management, U.S. Department of Energy, through Memorandum Purchase Order EA9013MC5X between Bechtel SAIC Company, LLC, and the Ernest Orlando Lawrence Berkeley National Laboratory (Berkeley Lab). The support is provided to Berkeley Lab through the U.S. Department of Energy Contract No. DE-AC03-76SF00098. Review and comments of Jens Birkholzer and Dan Hawkes from Berkeley Lab are greatly appreciated.

\section{References}

[1] Birkholzer, J.T. and Tsang, Y.W., Modeling the Thermal-Hydrologic Processes in a Large-Scale Underground Heater Test in Partially Saturated Fractured Tuff, Water Resources Research, 2000, 36(6), 1431-1447.

[2] Birkholzer, J.T., Mukhopadhyay, S., and Tsang, Y.W., Drift-Scale Coupled Processes (DST and TH Seepage) Models, MDL-NBS-HS-000015 REV01, Bechtel SAIC Company, Las Vegas, NV, 2004.

[3] BSC, Geologic Framework Model (GFM2000), MDL-NBS-GS-000002 REV 02, Bechtel SAIC Company, Las Vegas, Nevada, 2004a.

[4] BSC, Future Climate Analysis, ANL-NBS-GS-000008 REV 01, Bechtel SAIC Company, Las Vegas, Nevada, 2004b.

[5] Buscheck, T.A., Nitao, J.J., and Saterlie, S.F., Evaluation of ThermoHydrological Performance in Support of the Thermal Loading Systems Study, High Level Radioactive Waste Management, Proceedings of the Fifth Annual International Conference, Las Vegas, Nevada, May 22-26, 1994. 2, 592-610. American Nuclear Society, La Grange Park, Illinois, 1994.

[6] Buscheck, T.A., Rosenberg, N.D., Gansemer, J., and Sun, Y., Thermohydrologic Behavior at an Underground Nuclear Waste Repository, Water Resources Research, 2002, 38(3), 1-19.

[7] Doughty, C., Investigation of Conceptual and Numerical Approaches for Evaluating Moisture, Gas, Chemical, and Heat Transport in Fractured Unsaturated Rock, Journal of Contaminant Hydrology, 1999, 38(1-3), 69-106.

[8] Ghezzehei, T. A. and H. H. Liu, Calibrated Properties Model, MDL-NBS-HS000003 REV 02, Bechtel SAIC Company, Las Vegas, Nevada, 2004. 
[9] Haukwa, C.B., Wu, Y-S., and Bodvarsson, G.S., Thermal Loading Studies Using the Yucca Mountain Unsaturated Zone Model, Journal of Contaminant Hydrology, 1999, 38(1-3), 217-255.

[10] Haukwa, C.B., Wu, Y-S., and Bodvarsson, G.S., Modeling Thermal-Hydrological Response of the Unsaturated Zone at Yucca Mountain, Nevada, to Thermal Load at a Potential Repository, Journal of Contaminant Hydrology, 2003, 62-63, 529552.

[11] Liu, H.H., Doughty, C., and Bodvarsson, G.S., An Active Fracture Model for Unsaturated Flow and Transport in Fractured Rocks, Water Resources Research, 1998, 34(10), 2633-2646.

[12] Montazer, P. and Wilson, W.E., Conceptual Hydrologic Model of Flow in the Unsaturated Zone, Yucca Mountain, Nevada, Water-Resources Investigations Report 84-4345, U.S. Geological Survey, Lakewood, Colorado, 1984.

[13] Mukhophadhyay, S. and Tsang, Y.W., Understanding the Anomalous Temperature Data from the Large Block Test at Yucca Mountain, Nevada, Water Resources Research, 2002, 38(10), 28-1 through 28-12.

[14] Mukhophadhyay, S. and Tsang, Y.W., Uncertainties in Coupled ThermalHydrological Processes Associated with the Drift Scale Test at Yucca Mountain, Nevada, Journal of Contaminant Hydrology, 2003, 62-63, 595-612.

[15] Pan, L., Hinds, J., Haukwa, C.B., Wu, Y-S., and Bodvarsson, G.S., WinGridder An interactive grid generator for TOUGH, Version 1.0 User's Manual, LBNL42957, Lawrence Berkeley Laboratory, Berkeley, California, 2001.

[16] Pan, L. and Liu, H.H., Analysis of Hydrologic Properties Data, ANL-NBS-HS000042 REV 00, Bechtel SAIC Company, Las Vegas, Nevada, 2004.

[17] Pruess, K., TOUGH2-A General-Purpose Numerical Simulator for Multiphase Fluid and Heat Flow, LBL-29400, Lawrence Berkeley Laboratory, Berkeley, California, 1991.

[18] Pruess, K. and Narasimhan, T.N. 1985, A Practical Method for Modeling Fluid and Heat Flow in Fractured Porous Media, Society of Petroleum Engineers Journal, 1985, 25(1), 14-26.

[19] Pruess, K. and Tsang, Y., Thermal Modeling for a Potential High-Level Nuclear Waste Repository at Yucca Mountain, Nevada, LBL-35381, Lawrence Berkeley National Laboratory, Berkeley, California, 1994.

[20] Pruess, K., Wang, J.S.Y., and Tsang, Y.W., On Thermohydrologic Conditions Near High-Level Nuclear Wastes Emplaced in Partially Saturated Fractured Tuff, 1. Simulation Studies with Explicit Consideration of Fracture Effects, Water Resources Research, 1990a, 26(6), 1235-1248. 
[21] Pruess, K., Wang, J.S.Y., and Tsang, Y.W., On Thermohydrologic Conditions Near High-Level Nuclear Wastes Emplaced in Partially Saturated Fractured Tuff, 2. Effective Continuum Approximation, Water Resources Research, 1990b, 26(6), 1249-1261.

[22] Pruess, K., Oldenburg, C., and Moridis, G., TOUGH2 User’s Guide, Version 2.0, LBNL-43134, Lawrence Berkeley National Laboratory, Berkeley, California, 1999.

[23] Rousseau J. P., Kwicklis, E.M., and Gillies, C. (eds.), Hydrogeology of the unsaturated zone, North Ramp area of the exploratory studies facility, Yucca Mountain, Nevada, U.S. Geological Survey, Water-Resources Investigations 984050, 1998.

[24] Sass, J.H., Lachenbruch, A.H., Dudley, W.W., Jr., Priest, S.S., and Munroe, R.J., Temperature, Thermal Conductivity, and Heat Flow Near Yucca Mountain, Nevada: Some Tectonic and Hydrologic Implications, Open-File Report 87-649, U.S. Geological Survey, Denver, Colorado, 1988.

[25] Tsang, Y.W. and Pruess, K., A Study of Thermally Induced Convection near a High-Level Nuclear Waste Repository in Partially Saturated Fractured Tuff, Water Resources Research, 1987, 23(10), 1958-1966.

[26] Tsang, Y.W. and Birkholzer, J.T., Predictions and Observations of the ThermalHydrological Conditions in the Single Heater Test, Journal of Contaminant Hydrology, 1999, 38(1-3), 385-425.

[27] van Genuchten, M.T., A Closed-Form Equation for Predicting the Hydraulic Conductivity of Unsaturated Soils, Soil Science Society of America Journal, 1980, 44(5), 892-898.

[28] Warren, J.E. and Root, P.J., The Behavior of Naturally Fractured Reservoirs, Society of Petroleum Engineers Journal, 1963, 3(3), 245-255.

[29] Wu, Y. S., Chen, G., and Bodvarsson, G.S., Preliminary Analysis of Effects of Thermal Loading on Gas and Heat Flow within the Framework of LBNL/USGS Site-Scale Model, LBL-37729: UC-814, Lawrence Berkeley National Laboratory, Berkeley, California, 1995.

[30] Wu, Y.S., Haukwa, C., and Bodvarsson, G.S., A Site-Scale Model for Fluid and Heat Flow in the Unsaturated Zone of Yucca Mountain, Nevada, Journal of Contaminant Hydrology, 1999, 38(1-3), 185-215.

[31] Wu, Y. S., Pan, L., Zhang, W., and Bodvarsson, G.S., Characterization of Flow and Transport Processes within the Unsaturated Zone of Yucca Mountain, Nevada, Under Current and Future Climates, Journal of Contaminant Hydrology, 2002, 54(3-4), 215-247. 
[32] Wu, Y.S., G. Lu, K. Zhang, G. Zhang, H.H. Liu, T. Xu, and E.L. Sonnenthal, UZ Flow Models and Submodels, Research Report (AMR), MDL-NBS-HS-000006, REV02, Lawrence Berkeley National Laboratory, Berkeley, California, Bechtel SAIC Company, Las Vegas, Nevada, 2004a.

[33] Wu, Y. S., Lu, G., Zhang, K., and Bodvarsson, G.S., A Mountain-Scale Model for Characterizing Unsaturated flow and Transport in Fractured Tuffs of Yucca Mountain, Vadose Zone Journal, 2004b, 3, 796-805.

[34] Wu, Y.S, Mukhopadhyay, S., Zhang, K., Sonnenthal, E.L., Zhang, G., and Rutqvist, J., Mountain-Scale Coupled Processes (TH/THC/THM) Models, MDLNBS-HS-000007 REV03, Lawrence Berkeley National Laboratory, Berkeley, California, Bechtel SAIC Company, Las Vegas, NV, 2005. 
Table 1. Lithostratigraphy, TH model layer, and hydrogeologic unit correlation used in the mountain-scale TH model

\begin{tabular}{|c|c|c|}
\hline Major Unit & $\begin{array}{c}\text { Lithostratigraphic } \\
\text { Nomenclature }\end{array}$ & $\begin{array}{c}\text { TH Model Grid } \\
\text { Layer* }\end{array}$ \\
\hline \multirow{5}{*}{$\begin{array}{l}\text { Tiva Canyon welded } \\
\text { (TCw) }\end{array}$} & Tpcr & tcw11 \\
\hline & Трср & \multirow[t]{2}{*}{ tcw12 } \\
\hline & TpcLD & \\
\hline & Tpсpv3 & \multirow[t]{2}{*}{ tcw13 } \\
\hline & Трсрv2 & \\
\hline \multirow{10}{*}{$\begin{array}{l}\text { Paintbrush nonwelded } \\
\text { (PTn) }\end{array}$} & Трсрv1 & ptn21 \\
\hline & Tpbt4 & \multirow[t]{2}{*}{$\operatorname{ptn} 22$} \\
\hline & \multirow[t]{3}{*}{ Tpy (Yucca) } & \\
\hline & & ptn23 \\
\hline & & \multirow[t]{2}{*}{ ptn24 } \\
\hline & Tpbt3 & \\
\hline & Tpp (Pah) & ptn25 \\
\hline & Tpbt2 & \multirow[t]{3}{*}{ ptn26 } \\
\hline & Tptrv3 & \\
\hline & Tptrv2 & \\
\hline \multirow{11}{*}{$\begin{array}{l}\text { Topopah Spring welded } \\
\text { (TSw) }\end{array}$} & Tptrv1 & \multirow[t]{2}{*}{ tsw31 } \\
\hline & \multirow[t]{2}{*}{ Tptrn } & \\
\hline & & tsw32 \\
\hline & Tptrl, Tptf & \multirow[t]{2}{*}{ tsw33 } \\
\hline & Tptpul, RHHtop & \\
\hline & Tptpmn & tsw34 \\
\hline & Tptpll & tsw35 \\
\hline & \multirow[t]{2}{*}{ Tptpln } & tsw36 \\
\hline & & tsw37 \\
\hline & Tptpv3 & tsw38 \\
\hline & Tptpv2 & tsw39 (vit, zeo) \\
\hline \multirow{3}{*}{$\begin{array}{l}\text { Calico Hills nonwelded } \\
\text { (CHn) }\end{array}$} & Tptpv1 & \multirow[t]{2}{*}{ ch1 (vit, zeo) } \\
\hline & Tpbt1 & \\
\hline & Тас & ch2 (vit, zeo) \\
\hline
\end{tabular}




\begin{tabular}{|c|c|c|}
\hline Major Unit & $\begin{array}{l}\text { Lithostratigraphic } \\
\text { Nomenclature }\end{array}$ & $\begin{array}{c}\text { TH Model Grid } \\
\text { Layer* }\end{array}$ \\
\hline & \multirow[t]{3}{*}{ (Calico) } & ch3 (vit, zeo) \\
\hline & & ch4 (vit, zeo) \\
\hline & & ch5 (vit, zeo) \\
\hline & Tacbt (Calicobt) & ch6 (vit, zeo) \\
\hline & Tcpuv (Prowuv) & pp4 \\
\hline & Тсрuс (Prowuc) & pp3 \\
\hline & Tcpmd (Prowmd) & \multirow[t]{2}{*}{ pp2 } \\
\hline & Tcplc (Prowlc) & \\
\hline & Tcplv (Prowlv) & \multirow[t]{3}{*}{ pp1 } \\
\hline & Tcpbt (Prowbt) & \\
\hline & Tcbuv (Bullfroguv) & \\
\hline \multirow{11}{*}{$\begin{array}{l}\text { Crater Flat undifferentiated } \\
\text { (CFu) }\end{array}$} & Tcbuc (Bullfroguc) & bf3 \\
\hline & Tcbmd (Bullfrogmd) & \\
\hline & Tcblc (Bullfroglc) & \\
\hline & Tcblv (Bullfroglv) & \multirow[t]{3}{*}{ bf2 } \\
\hline & Tcbbt (Bullfrogbt) & \\
\hline & Tctuv (Tramuv) & \\
\hline & Tctuc (Tramuc) & \multirow[t]{3}{*}{ tr3 } \\
\hline & Tctmd (Trammd) & \\
\hline & Tctlc (Tramlc) & \\
\hline & Tctlv (Tramlv) & \multirow[t]{2}{*}{ tr2 } \\
\hline & Tctbt (Trambt) and below & \\
\hline
\end{tabular}

Table 2. Averaged infiltration rates (mm/yr) and time period over the TH model domain

\begin{tabular}{|c|c|c|}
\hline Scenario & Time Period & $\begin{array}{c}\text { Mean Infiltration } \\
\text { (mm/yr) }\end{array}$ \\
\hline Present-Day/Modern & 0-600 Years & 3.6 \\
\hline Monsoon & $600-2,000$ Years & 10.4 \\
\hline Glacial Transition & 2,000 and beyond & 16.1 \\
\hline
\end{tabular}




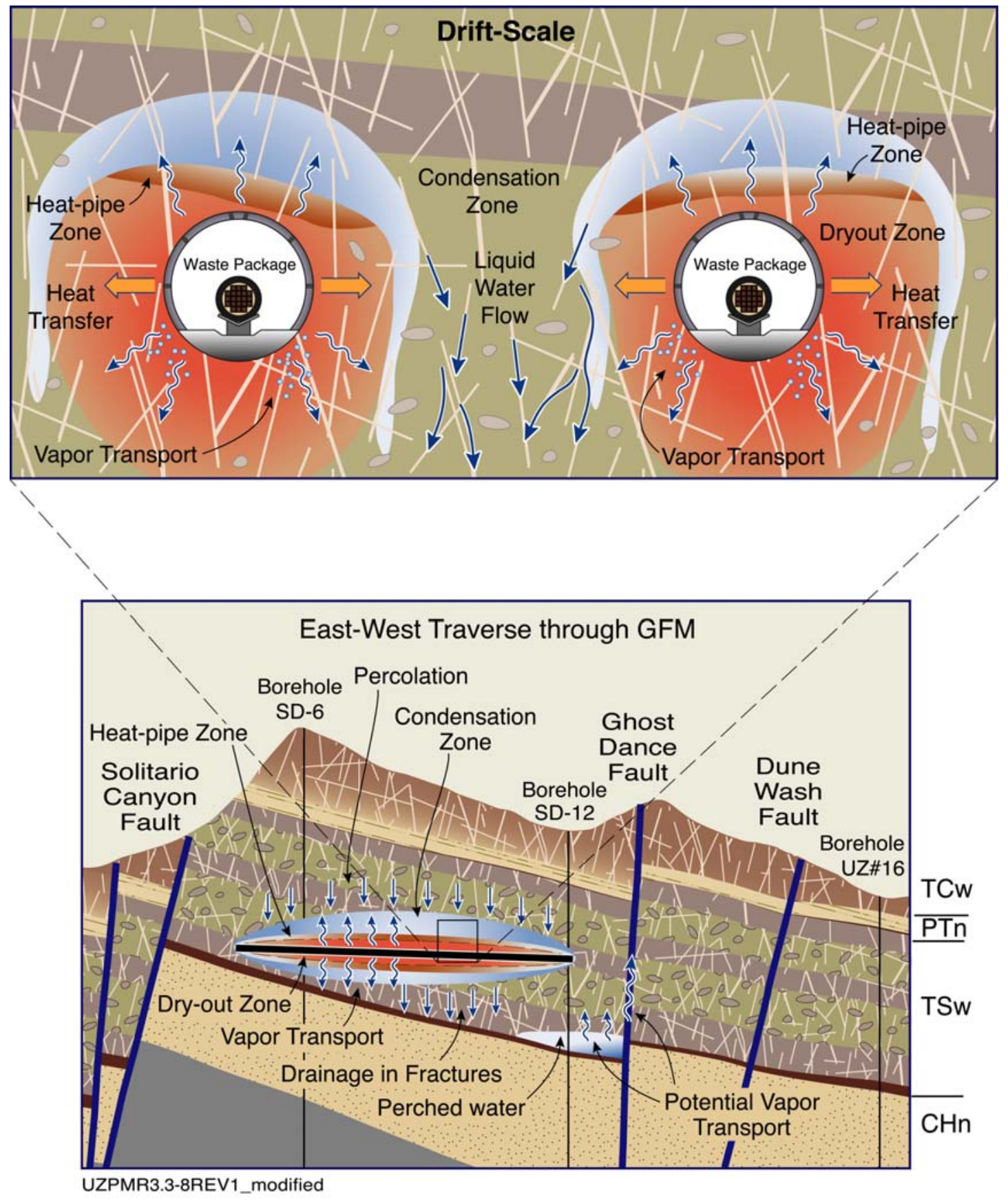

Figure 1. Schematic representation of the mountain-scale (Bottom) and drift-scale (Top) $\mathrm{TH}$ processes likely to occur in the unsaturated fractured rock of Yucca Mountain 


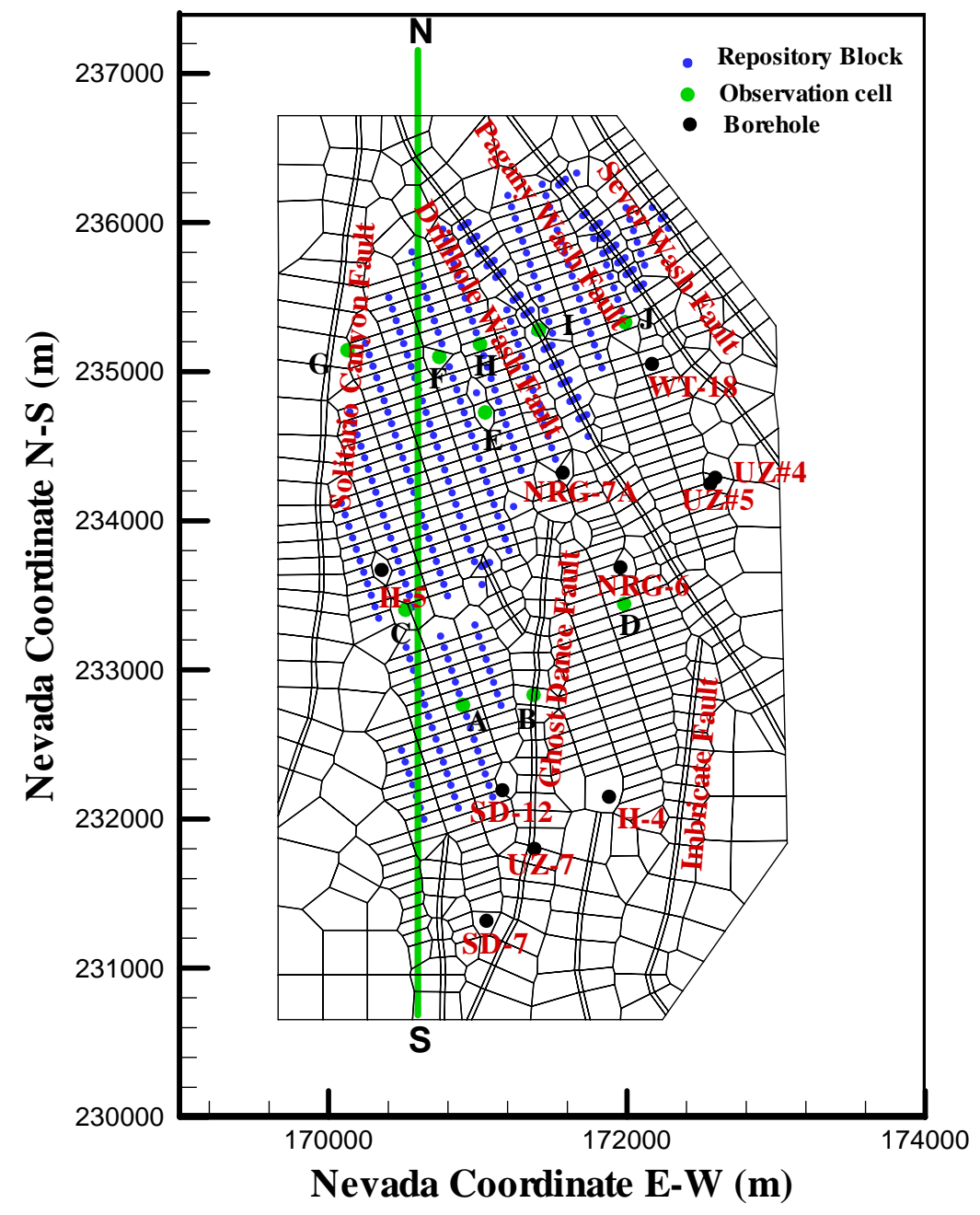

Figure 2. Plan view of the three-dimensional TH model grid showing the model domain, faults incorporated, several borehole locations, and TH model boundaries (The North-South green line is a trace of the two-dimensional model grid shown in Figure 3) 


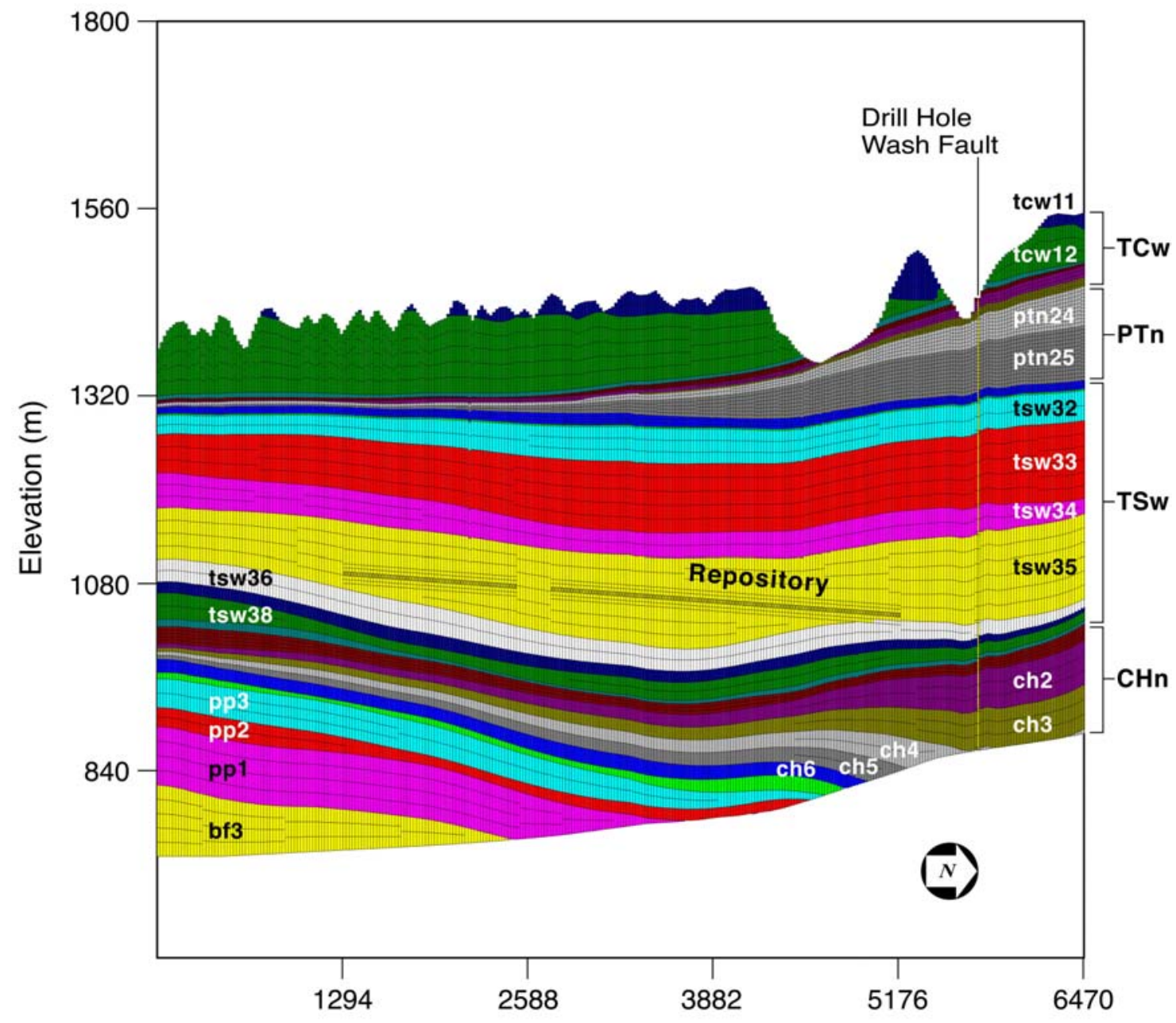

Horizontal Distance $(\mathrm{m})$ from point(170600,230673)

Figure 3. Two-dimensional N-S cross-sectional model domain and grid showing lateral and vertical discretization, hydrogeological layers, repository layout, and a fault (See Figure 2 for the cross section location) 


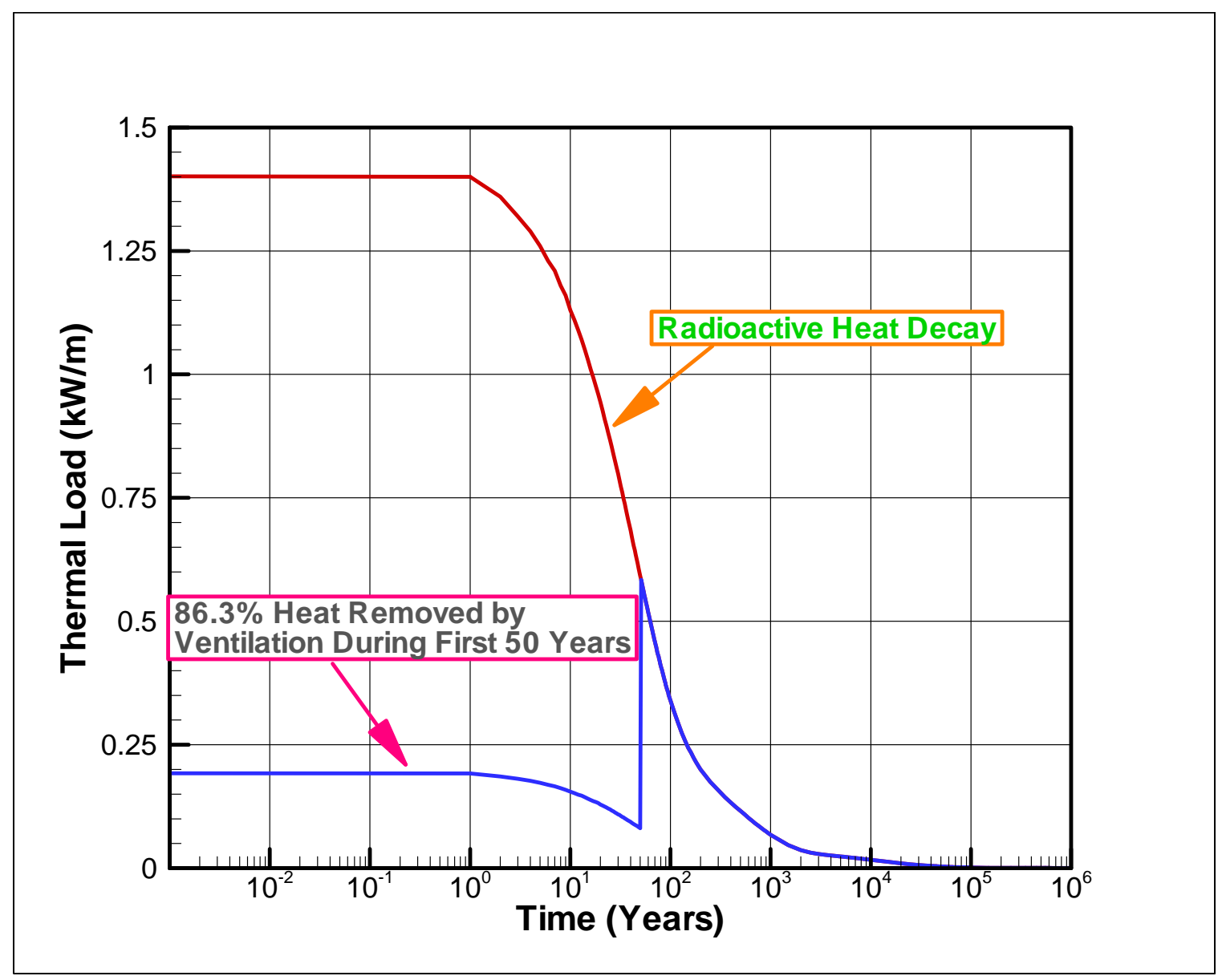

Figure 4. Radioactive heat decay curve for an initial thermal load of $1.45 \mathrm{~kW} / \mathrm{m}$. showing the thermal load when $86.3 \%$ of the heat is removed by ventilation during the first 50 years 


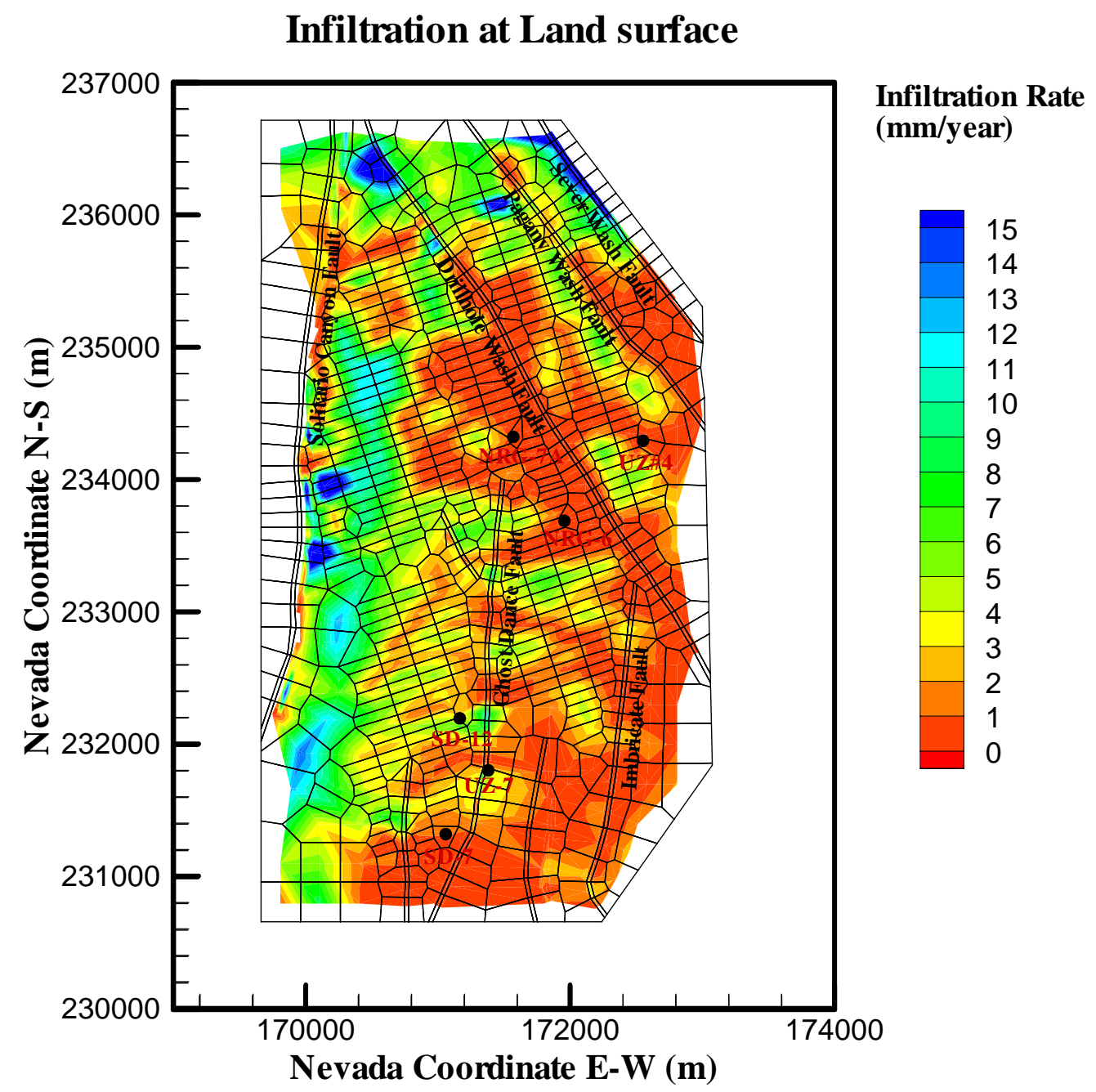

Figure 5. Plan view of net surface infiltration distributed over the 3-D TH model domain for the present-day mean infiltration scenario, used for ambient TH model calibration as well as for the first 600 years of thermal loading. The blcak solid circles represent the location of the boreholes 

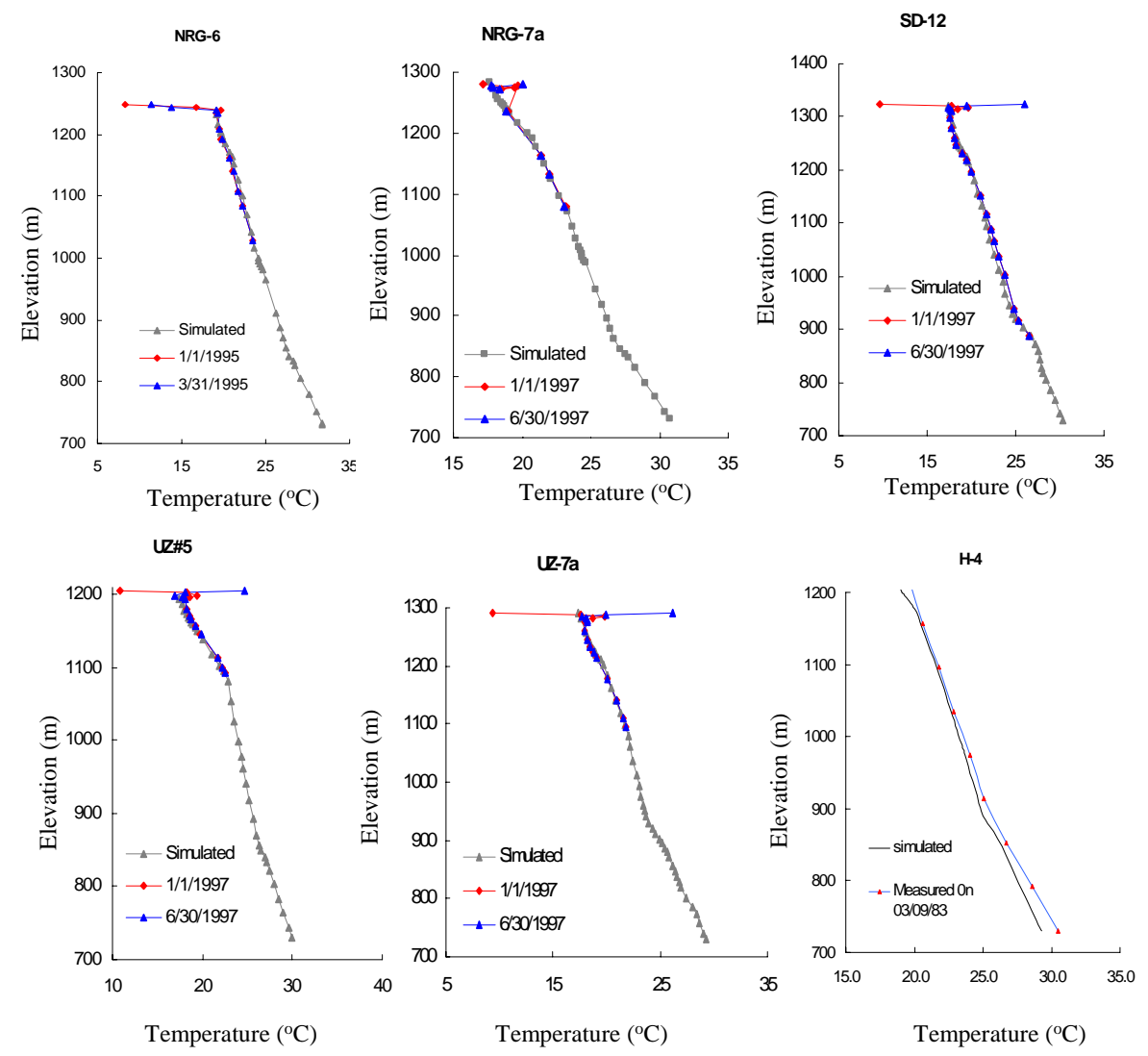

Figure 6. Comparisons between measured and simulated ambient temperature profiles for six boreholes under the present-day mean infiltration rate 


\section{Temperature Distribution at Repository Honizon (100 years, $\mathrm{nv}$ )}

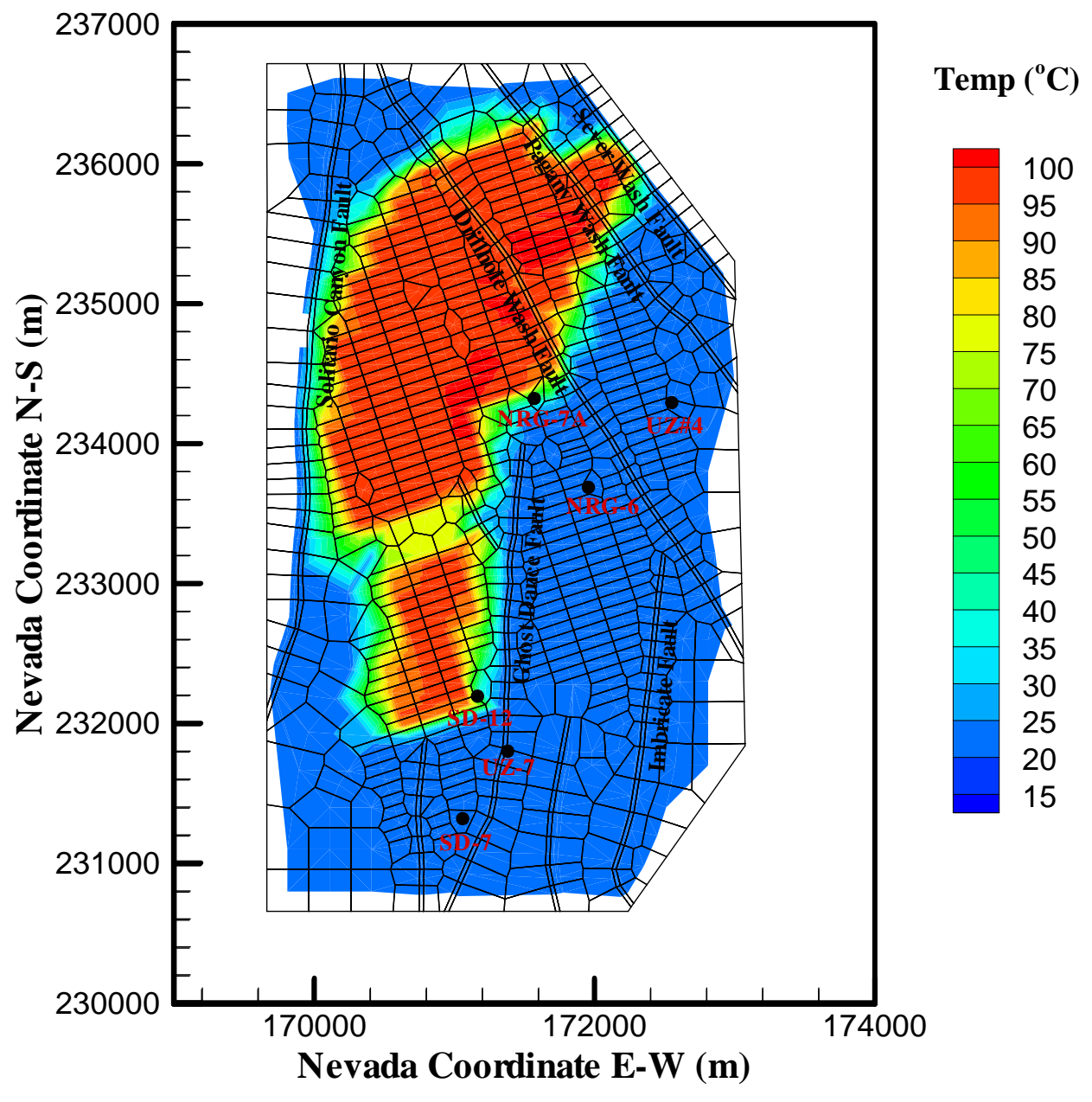

Figure 7a. Rock temperature distribution at the repository horizon 100 years after waste emplacement as predicted by the 3-D mountain-scale th model 


\section{Temperature Distribution at Repository Horizon (1000 year, nv)}

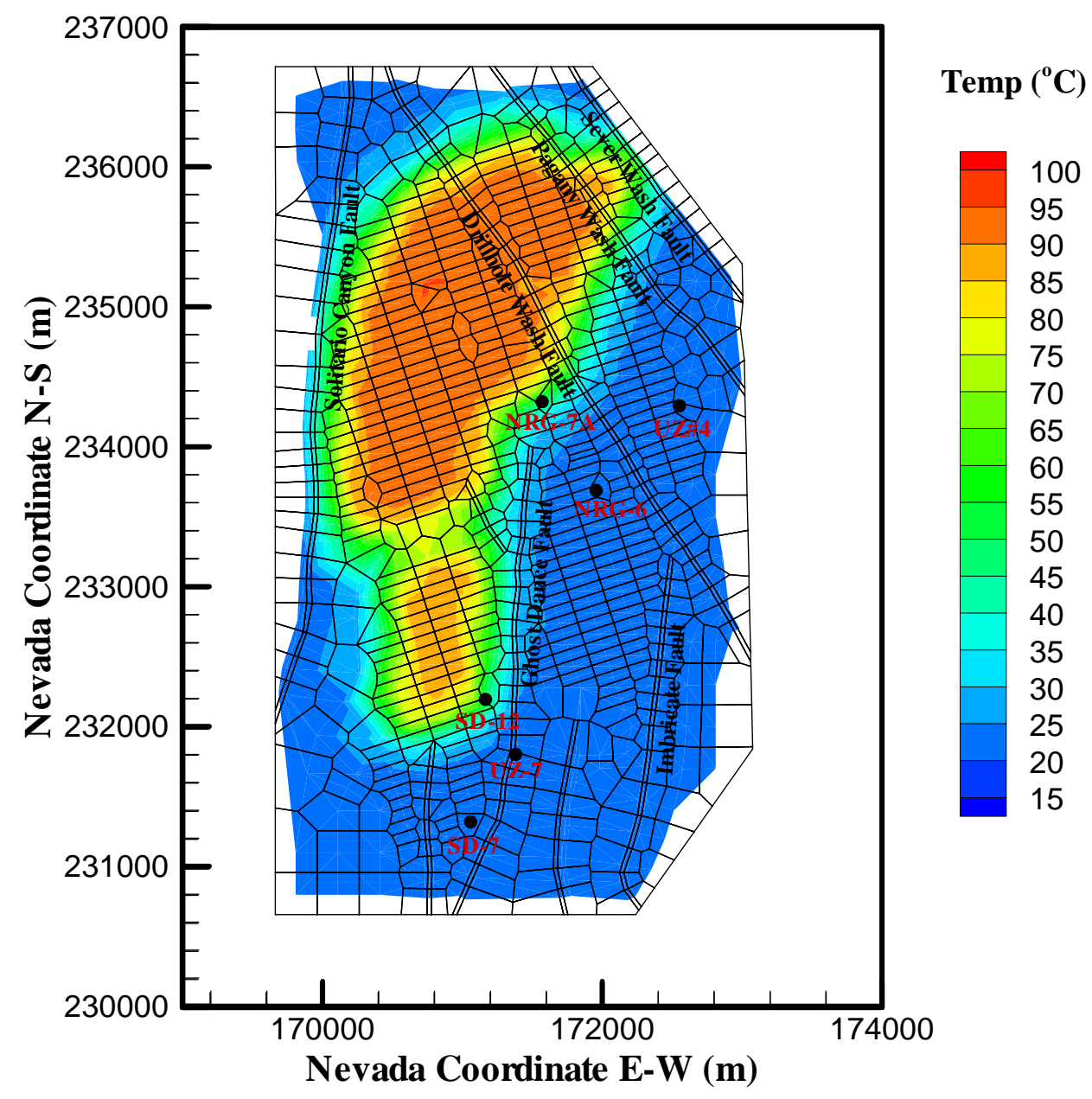

Figure 7b. Rock temperature distribution at the repository horizon 1,000 years after waste emplacement as predicted by the 3-D mountain-scale TH model 


\section{Temperature Distribution at Repository Horizon}

(5000 years, $\mathrm{nv}$ )

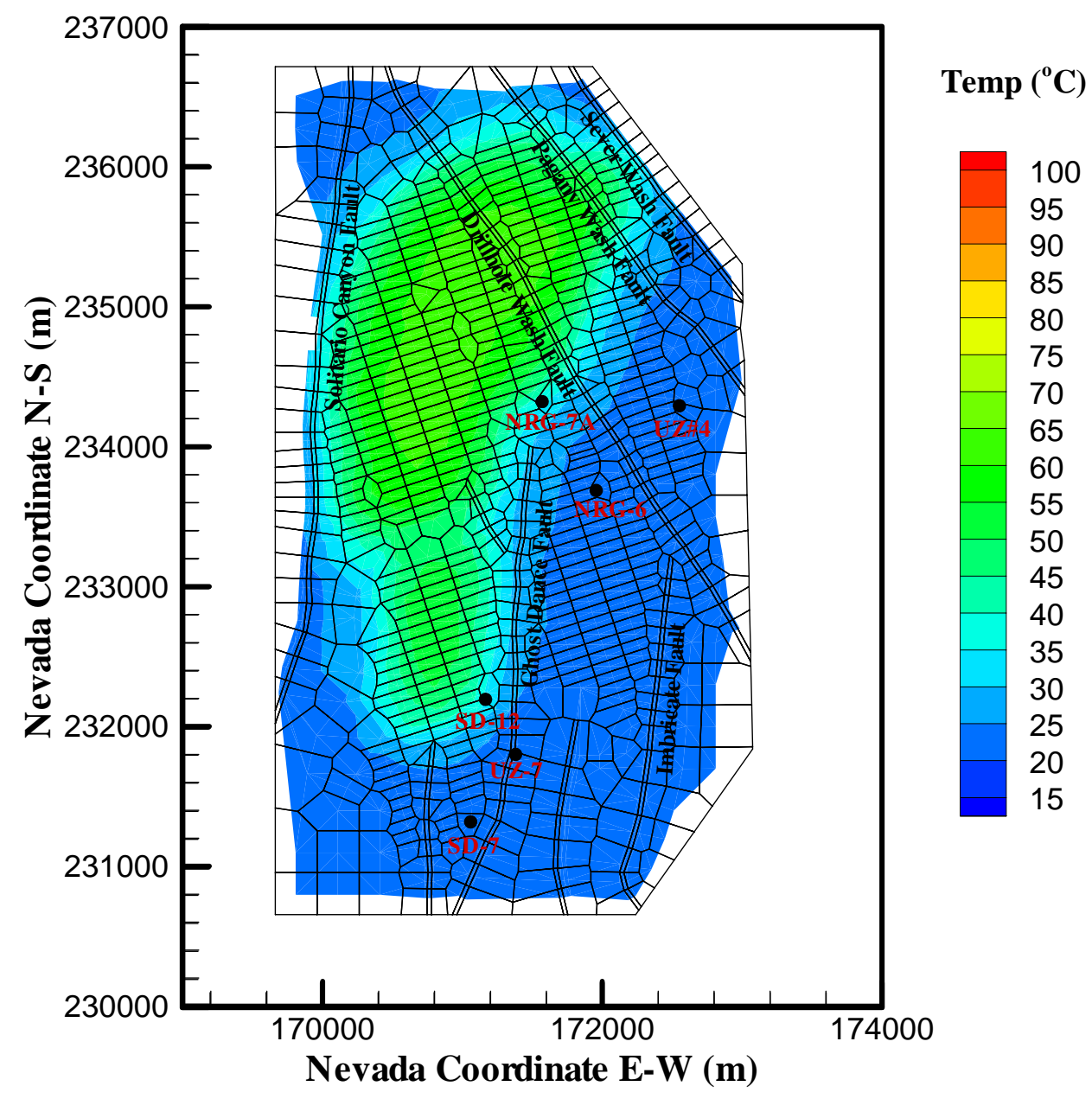

Figure 7c. Rock temperature distribution at the repository horizon 5,000 years after waste emplacement as predicted by the 3-D mountain-scale TH model 


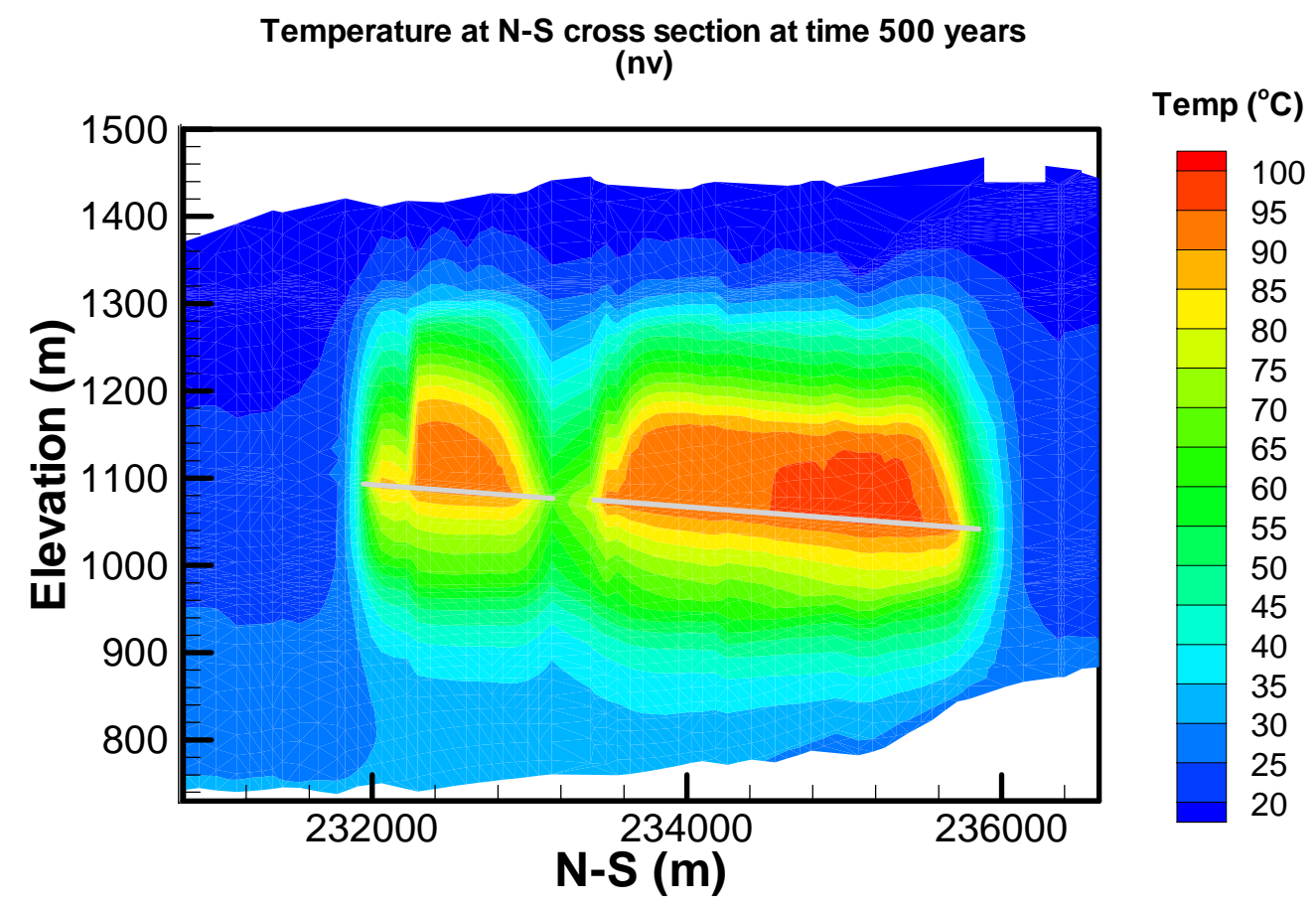

Figure 8a. Rock temperature distribution at the n-s cross section 500 years after waste emplacement as predicted by the 3-D mountain-scale TH model 


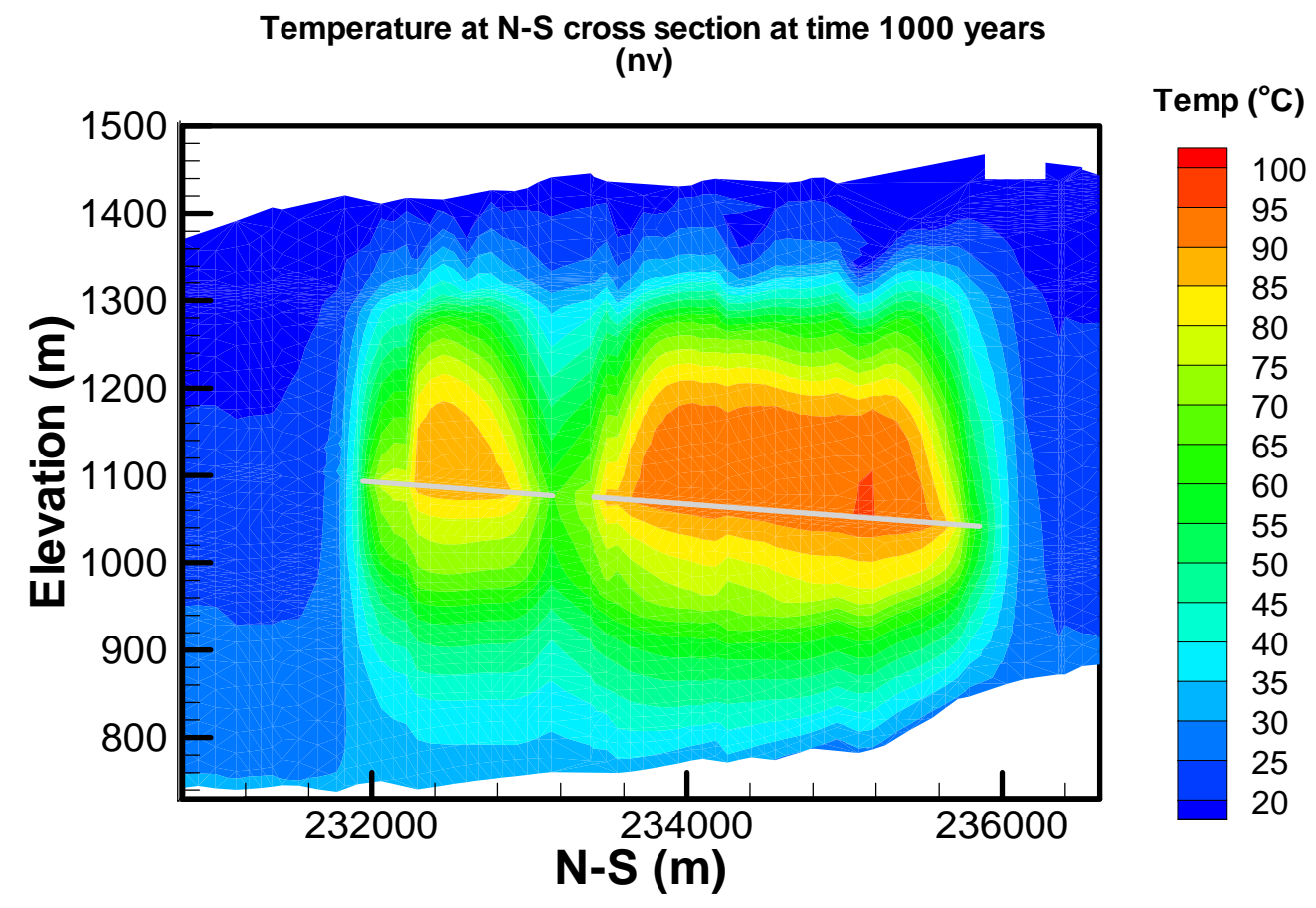

Figure 8b. Rock temperature distribution at the n-s cross section 1,000 years after waste emplacement as predicted by the 3-D mountain-scale TH model 


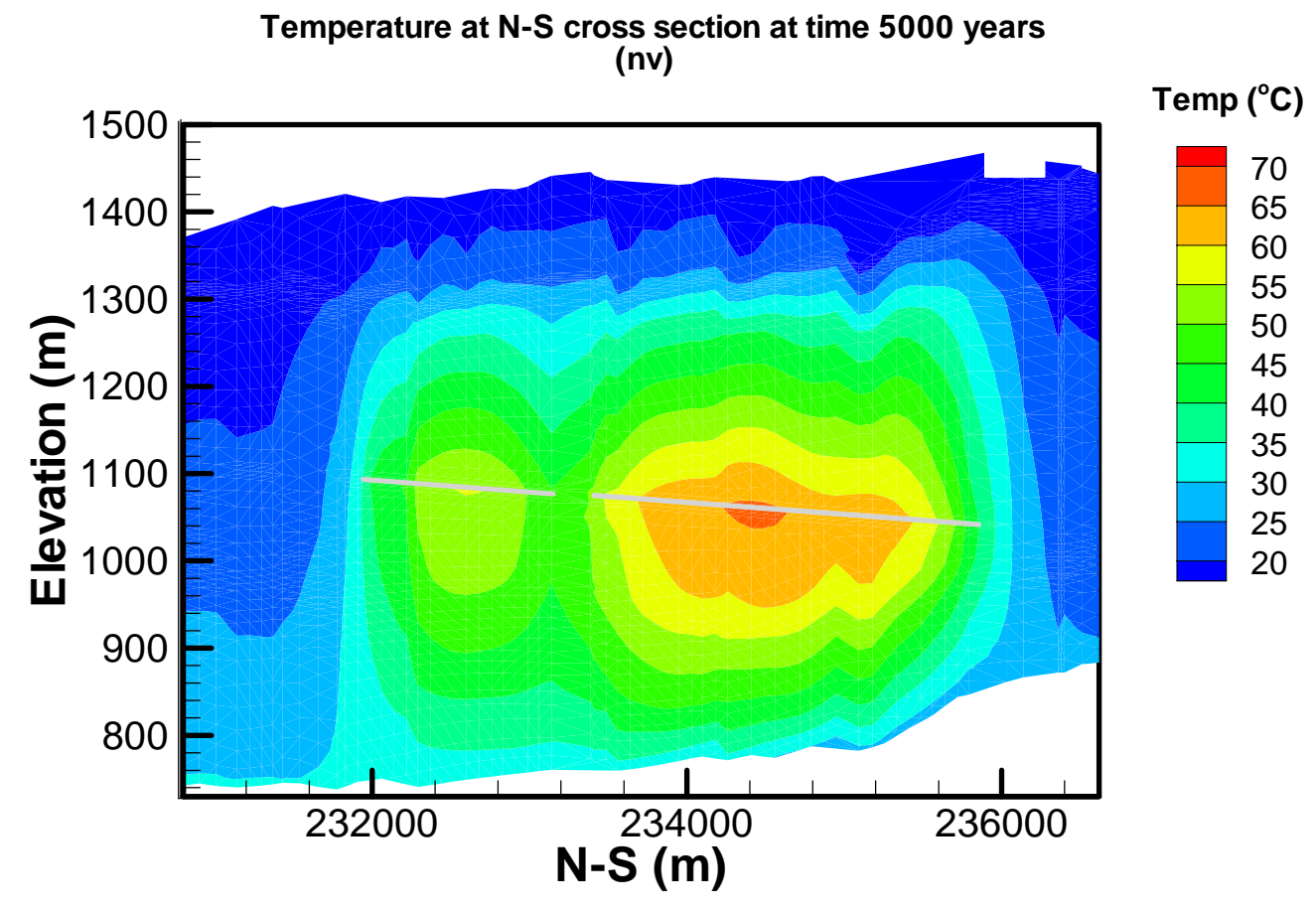

Figure 8c. Rock temperature distribution at the n-s cross section 5,000 years after waste emplacement as predicted by the 3-D mountain-scale TH model 


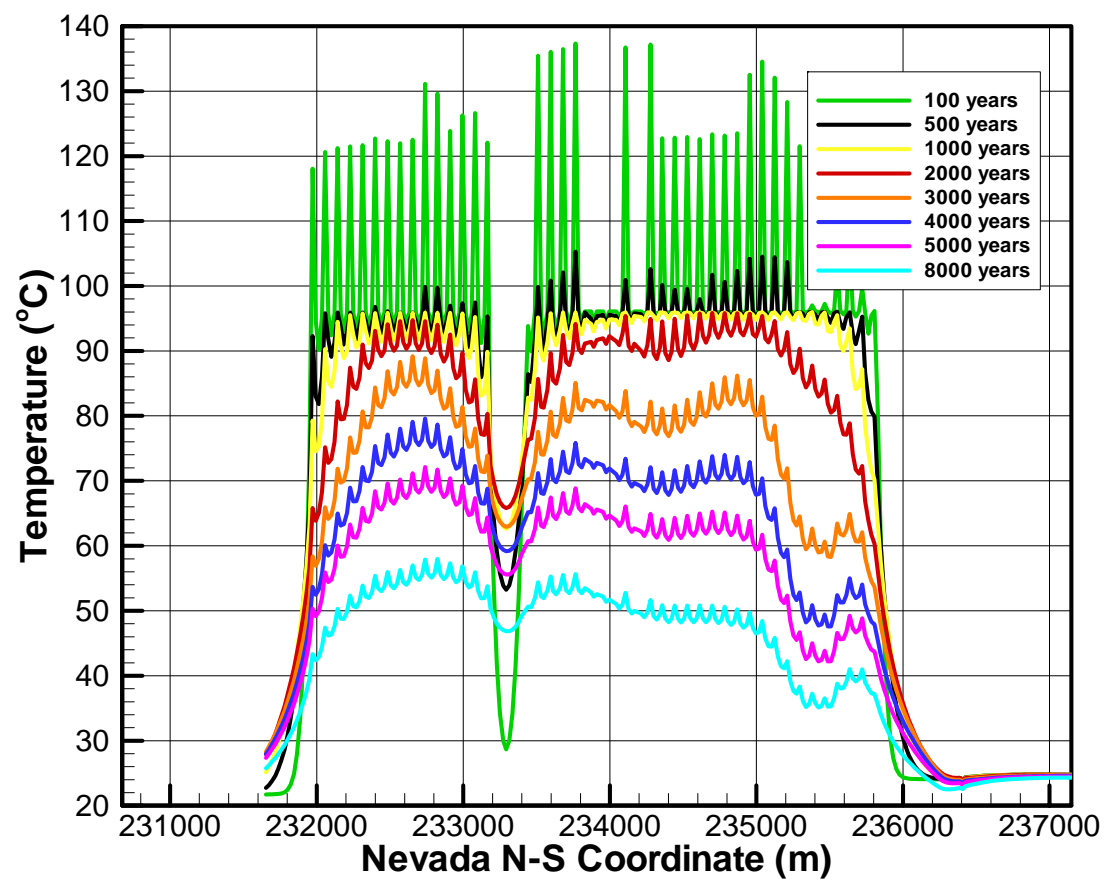

Figure 9a. Rock temperatures just above the emplacement drifts as predicted by the 2-D mountain-scale TH model without ventilation 


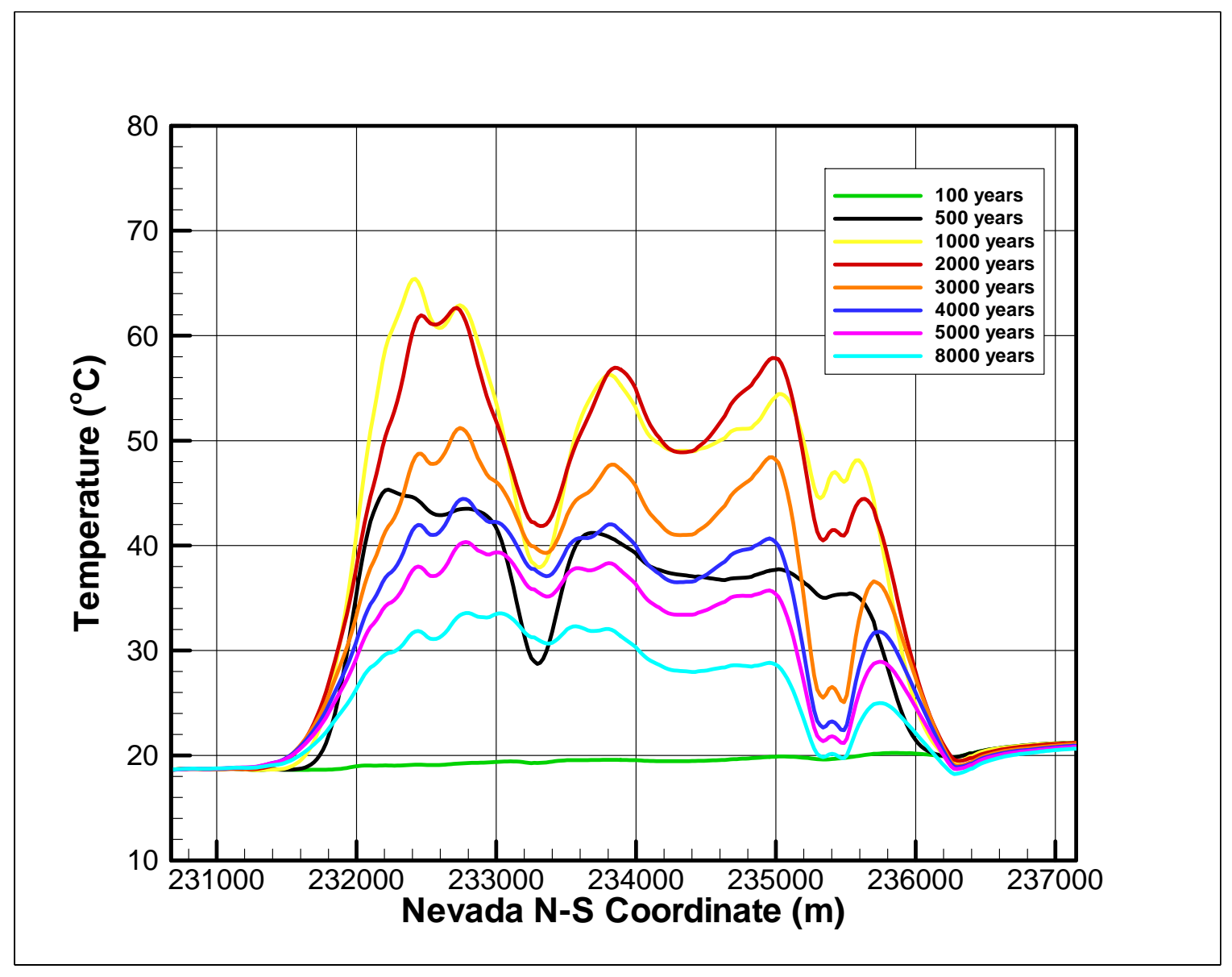

Figure 9b. Rock temperatures at the bottom of ptn as predicted by the 2-D mountainscale TH model without ventilation 


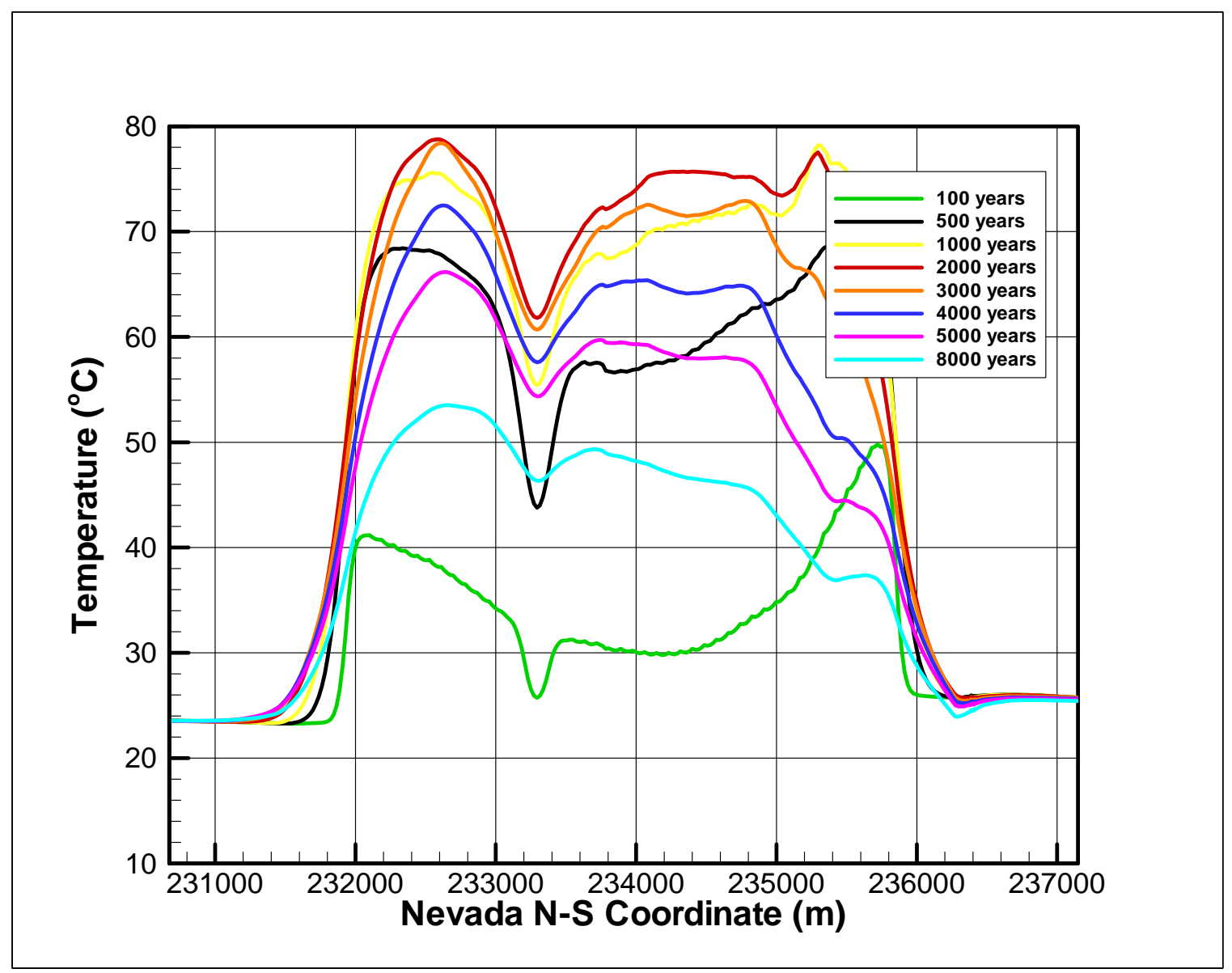

Figure 9c. Rock temperatures at the top of chn as predicted by the 2-D mountain-scale TH model without ventilation. 


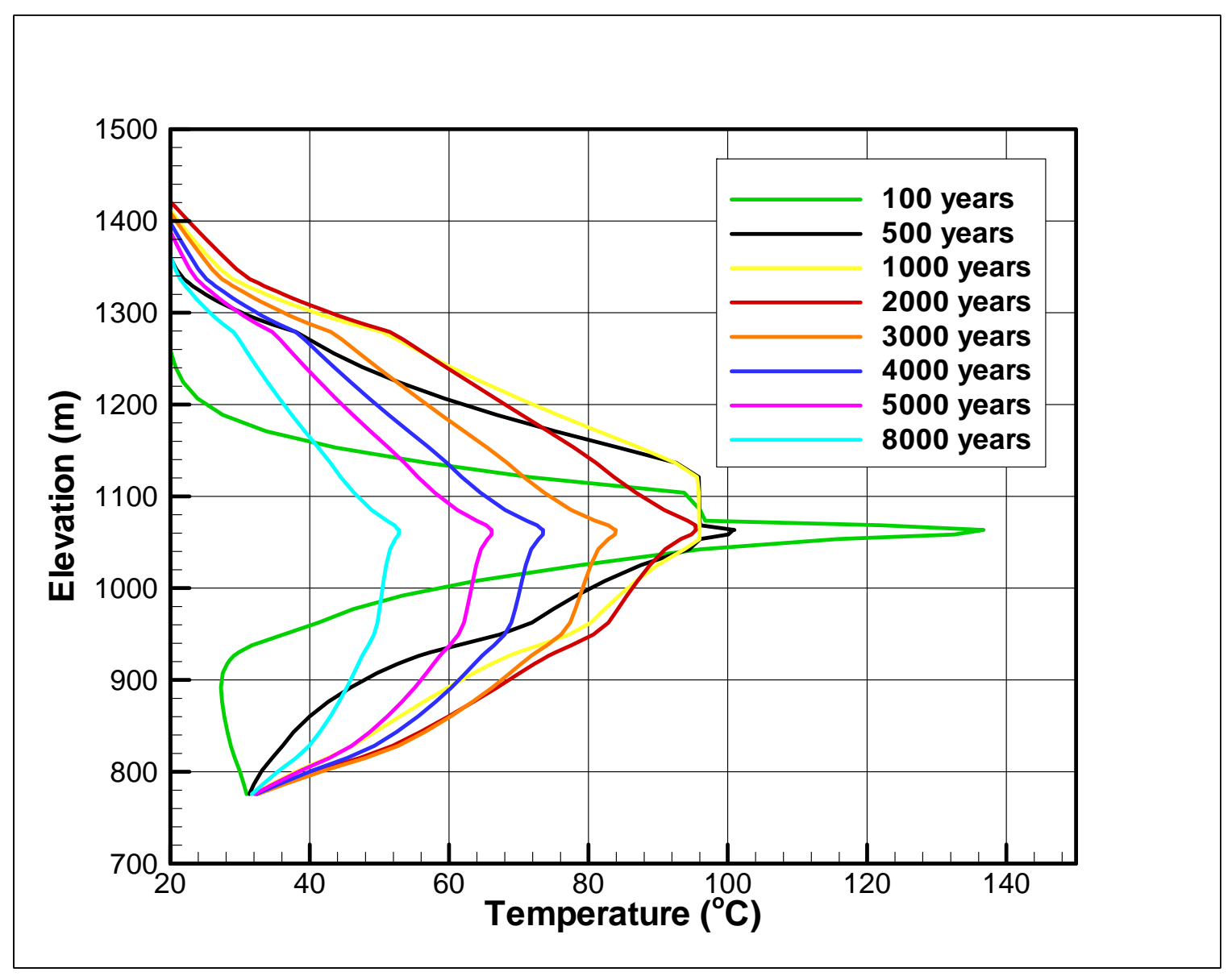

Figure 9d. Rock temperature along a vertical column from the ground surface to water table as predicted by the 2-D mountain-scale TH model without ventilation 

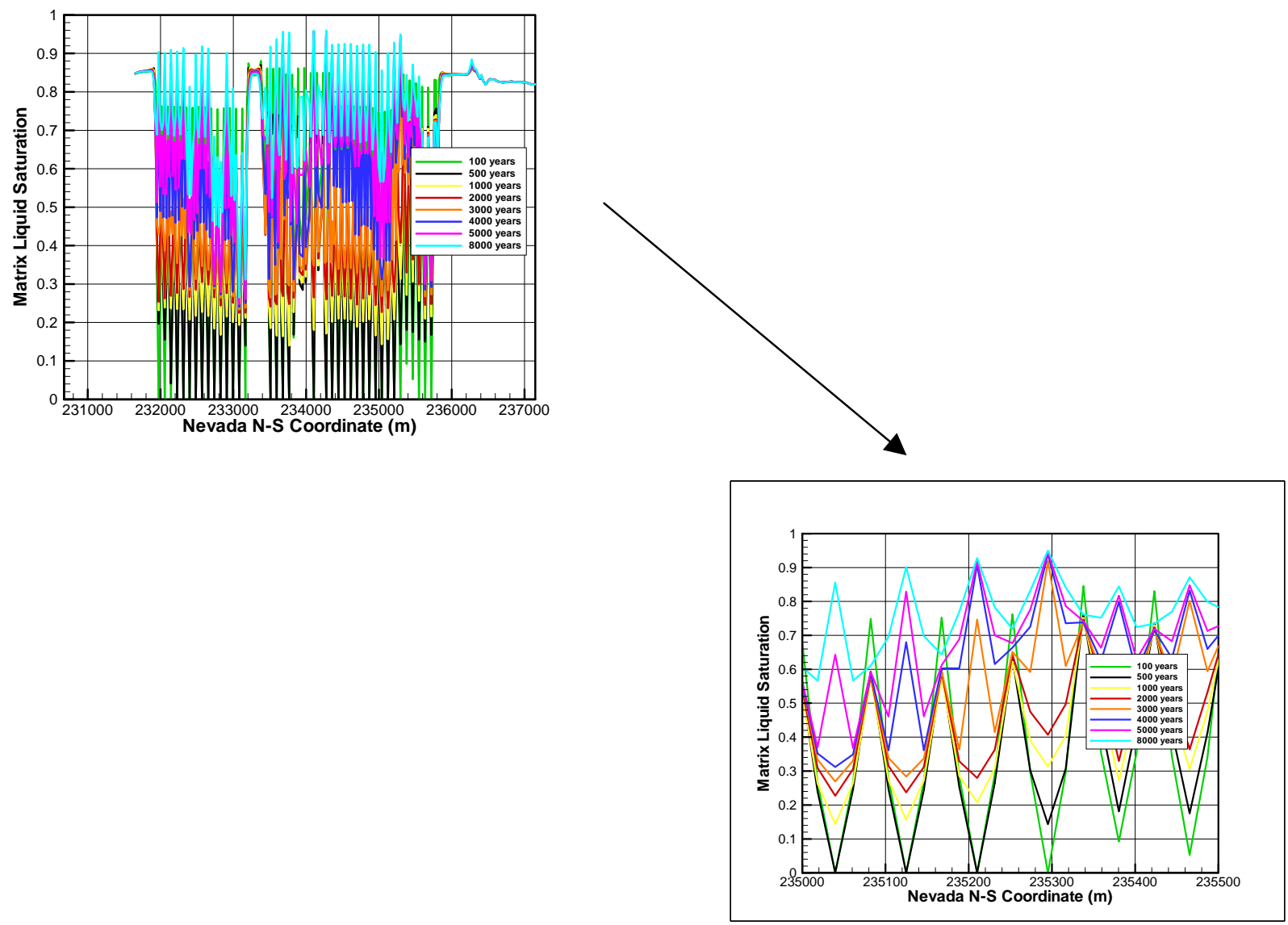

Figure 10a. Matrix liquid saturation along the north-south axis just above the emplacement drifts as predicted by the 2-D mountain-scale TH model without ventilation (top). A close-up view of the same is shown at the bottom. 


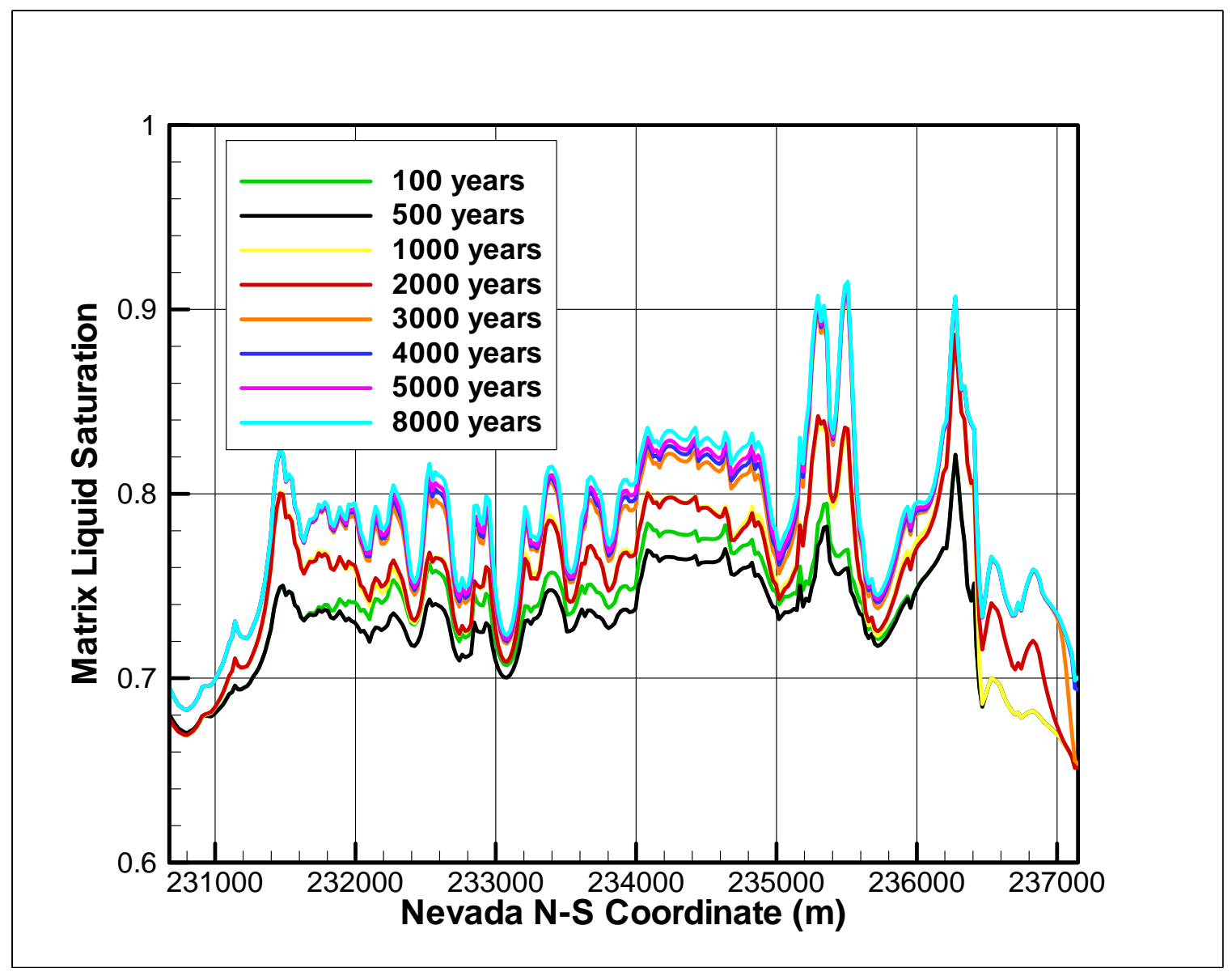

Figure 10b. Matrix liquid saturation at the bottom of ptn as predicted by the 2-D mountain-scale TH model without ventilation 


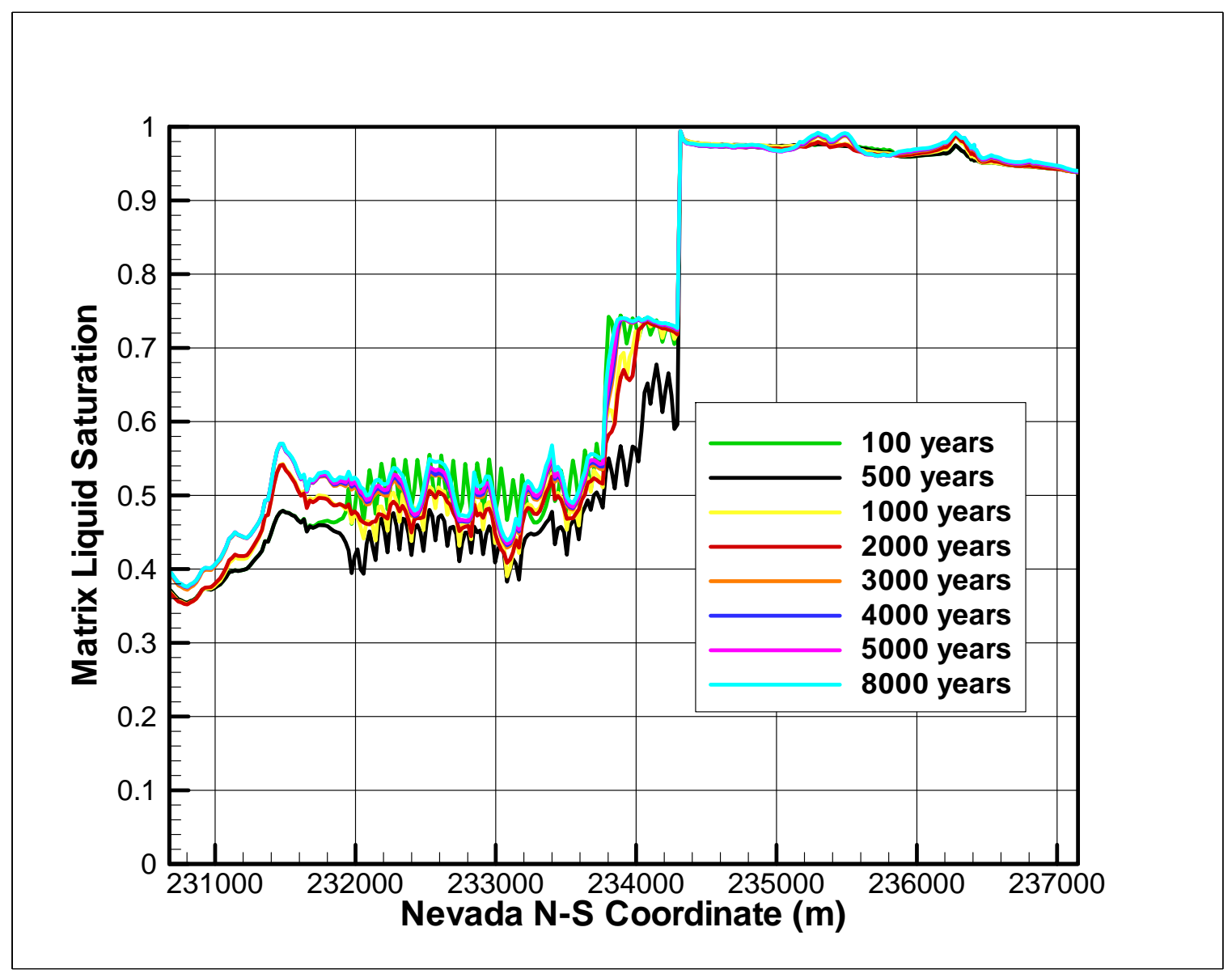

Figure 10c. Matrix liquid saturation at the top of $\mathrm{CHn}$ as predicted by the 2-D mountainscale TH model without ventilation 


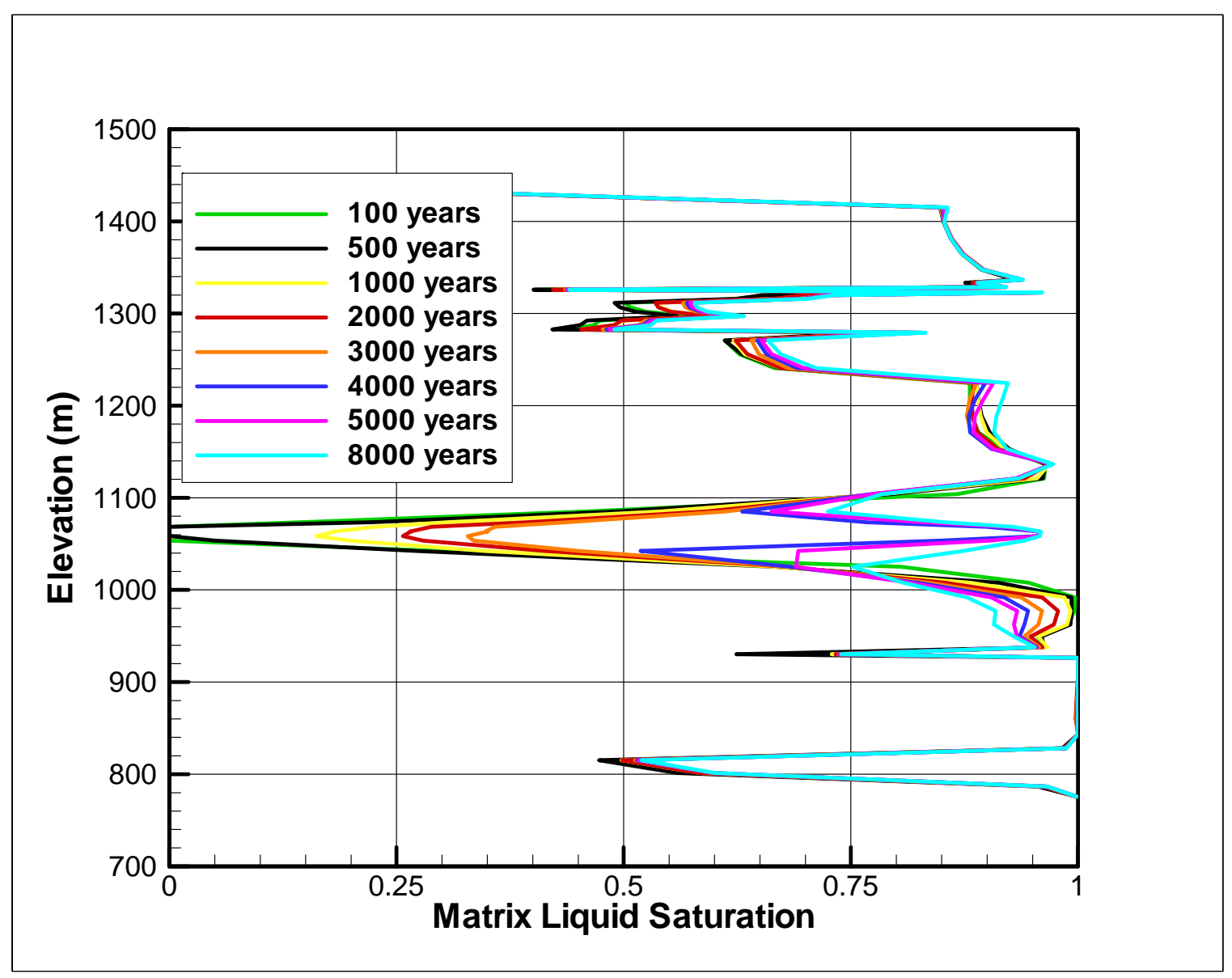

Figure 10d. Matrix saturation along a vertical column from the ground surface to water table as predicted by the 2-D mountain-scale TH model without ventilation 


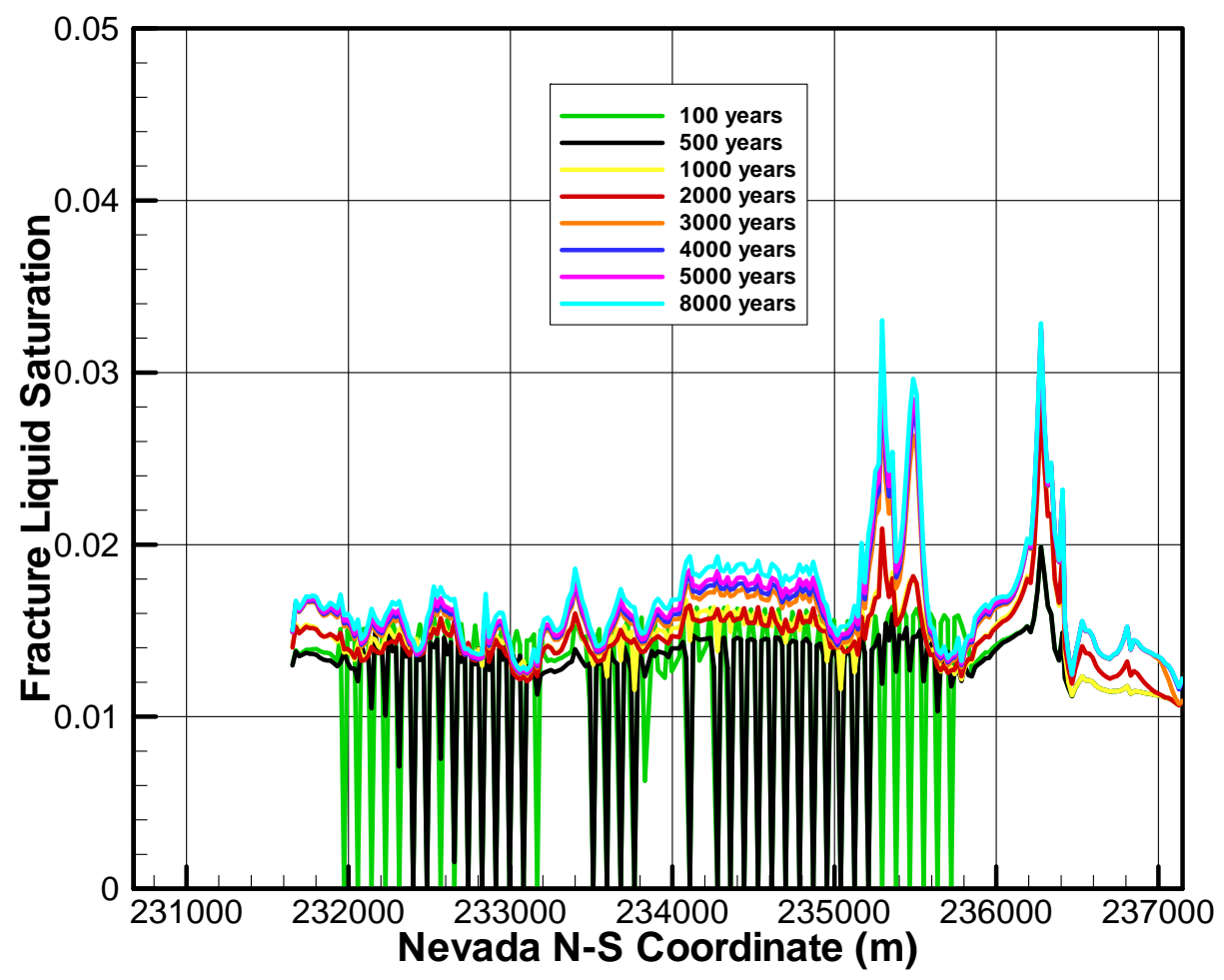

Figure 11a. Fracture liquid saturation just above the emplacement drifts as predicted by the 2-D mountain-scale TH model without ventilation 


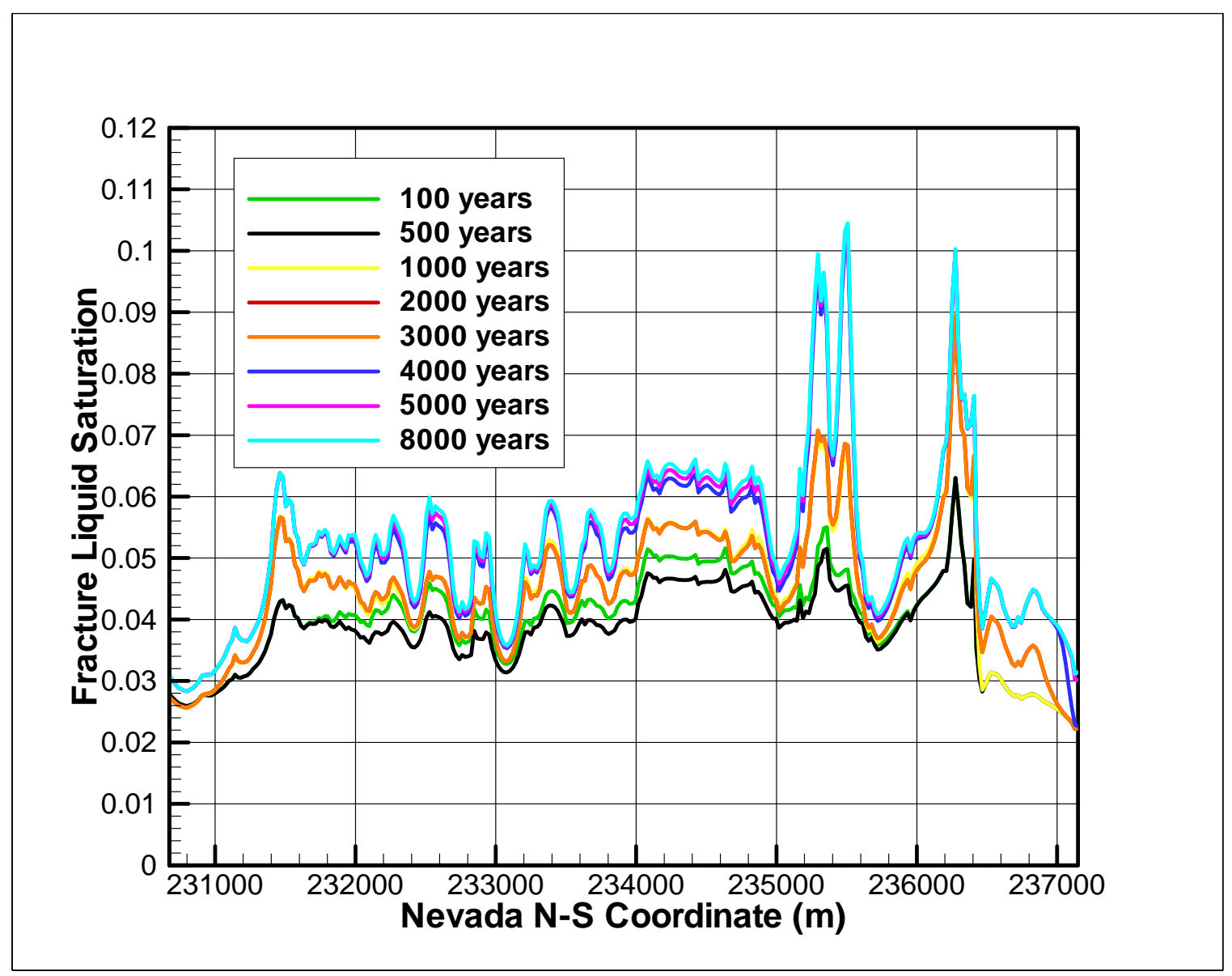

Figure 11b. Fracture liquid saturation at the bottom of ptn as predicted by the 2-D mountain-scale TH model without ventilation 


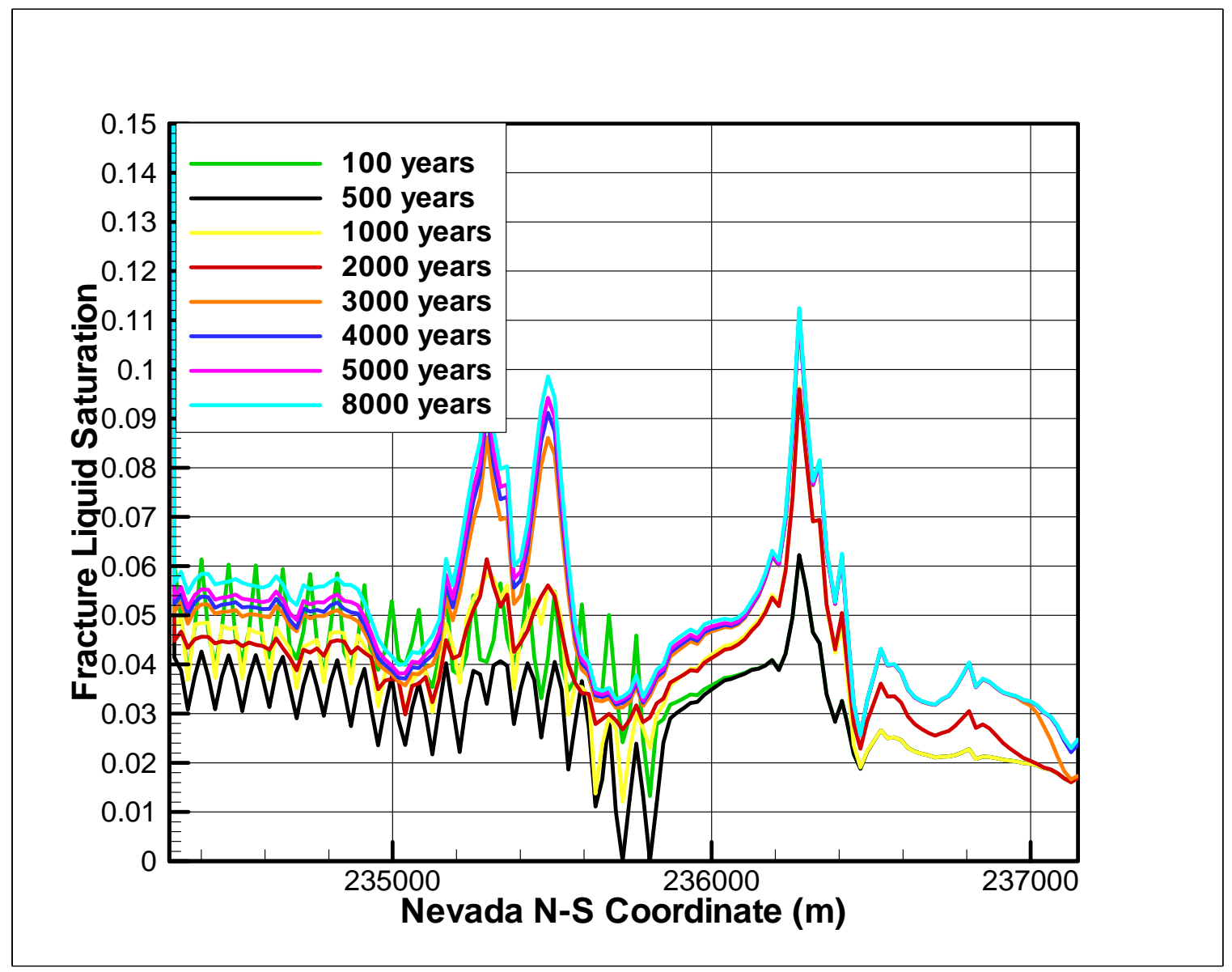

Figure 11c. Fracture liquid saturation at the top of chn as predicted by the 2-D mountain-scale TH model without ventilation 


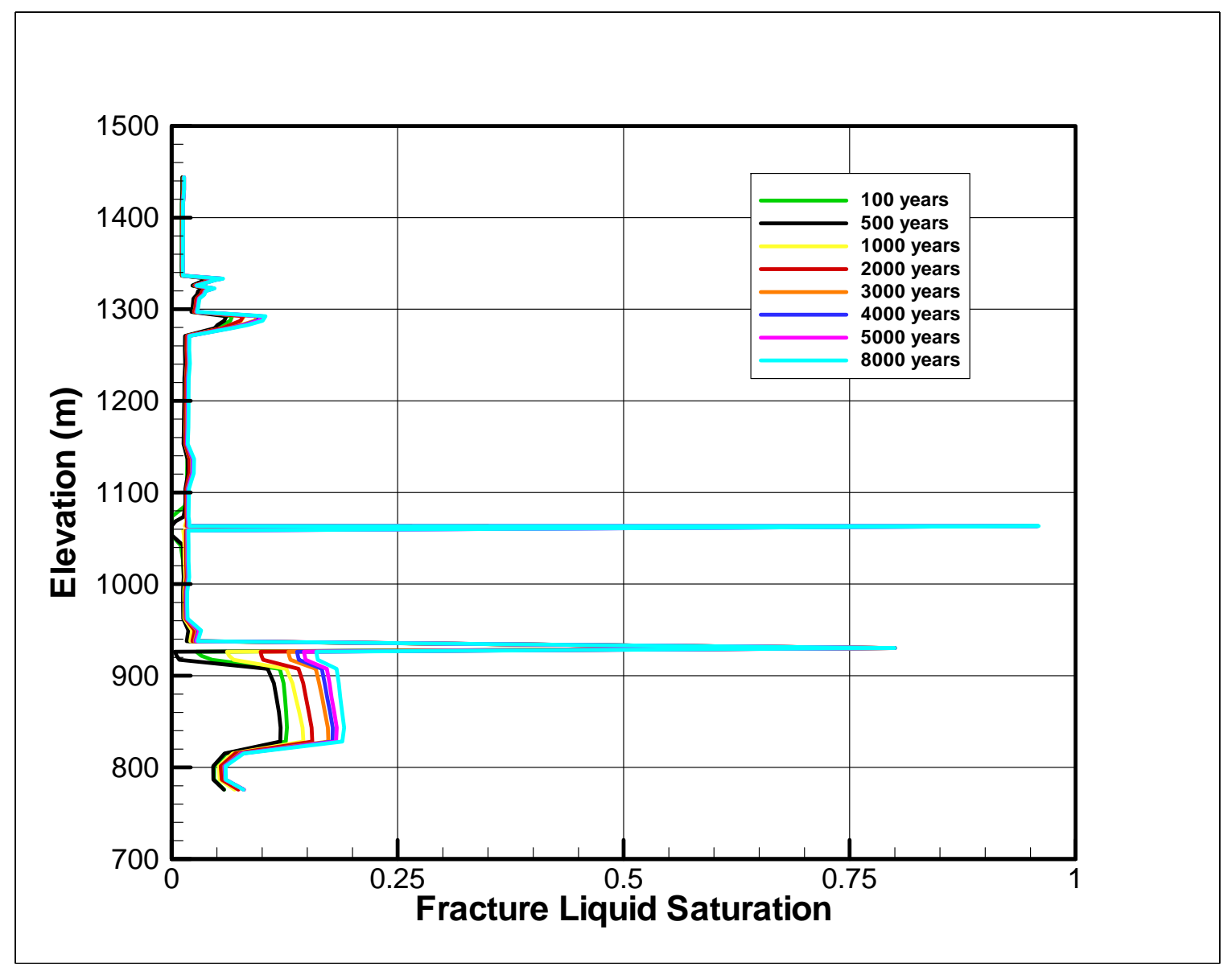

Figure 11d. Fracture saturation along a vertical column from the ground surface to water table as predicted by the 2-D mountain-scale TH model without ventilation 


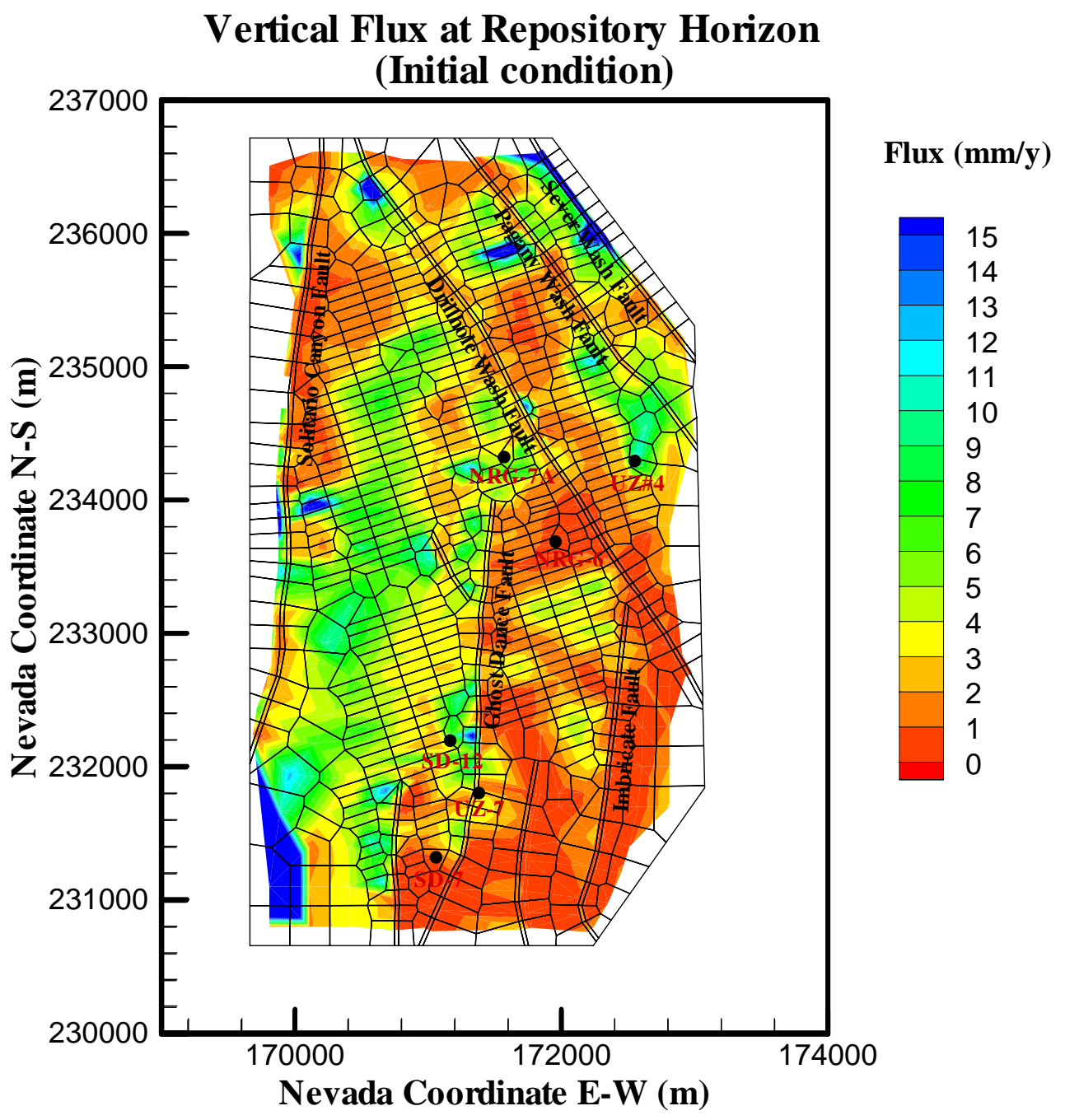

Figure 12a. Total vertical flux distribution at repository horizon under ambient conditions with the present-day, mean infiltration rates (Table 2) as predicted by the 3-D mountain-scale TH model 


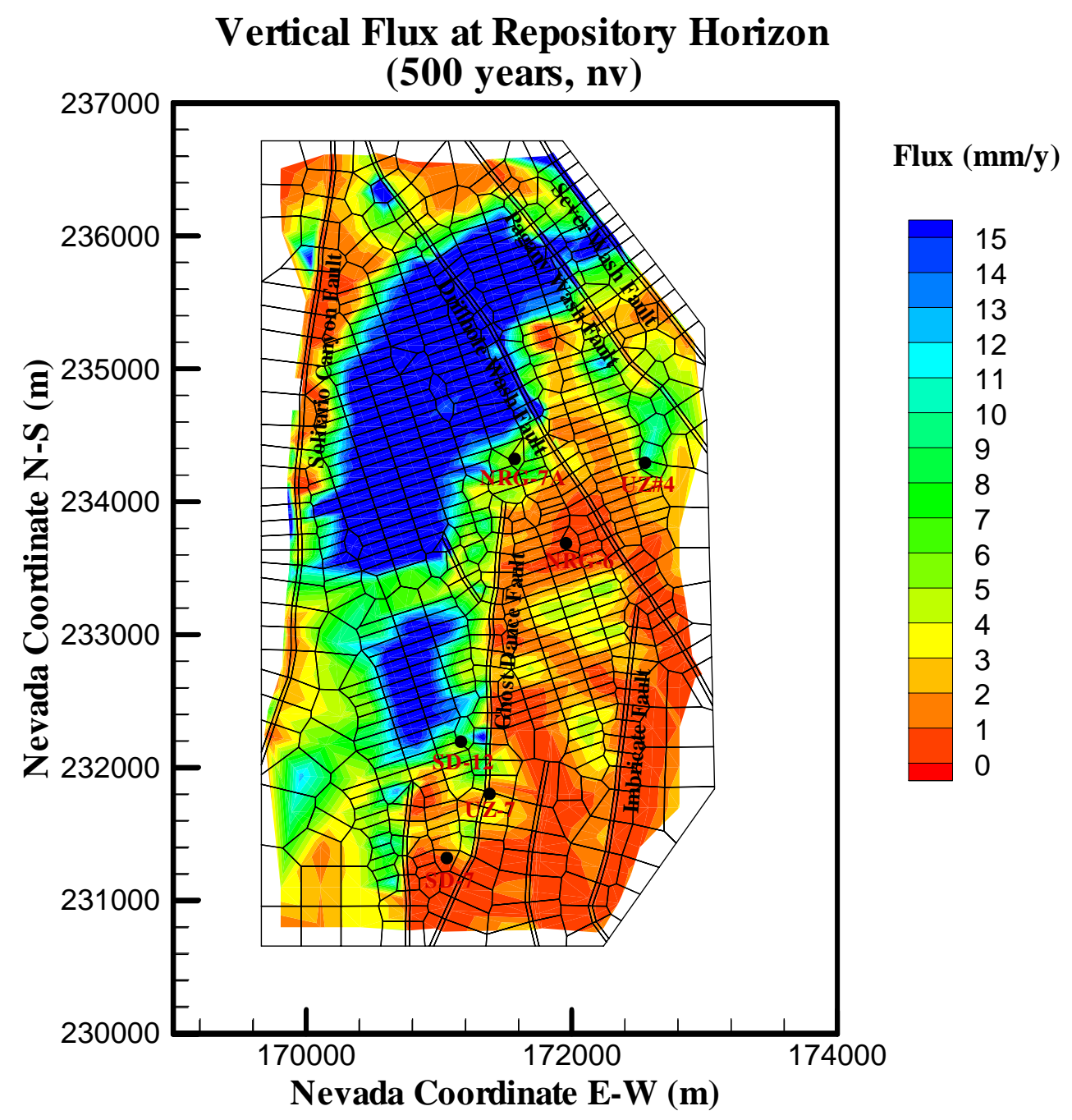

Figure 12b. Total vertical flux distribution at repository horizon 500 years after waste emplacement as predicted by the 3-D mountain-scale TH model without ventilation 


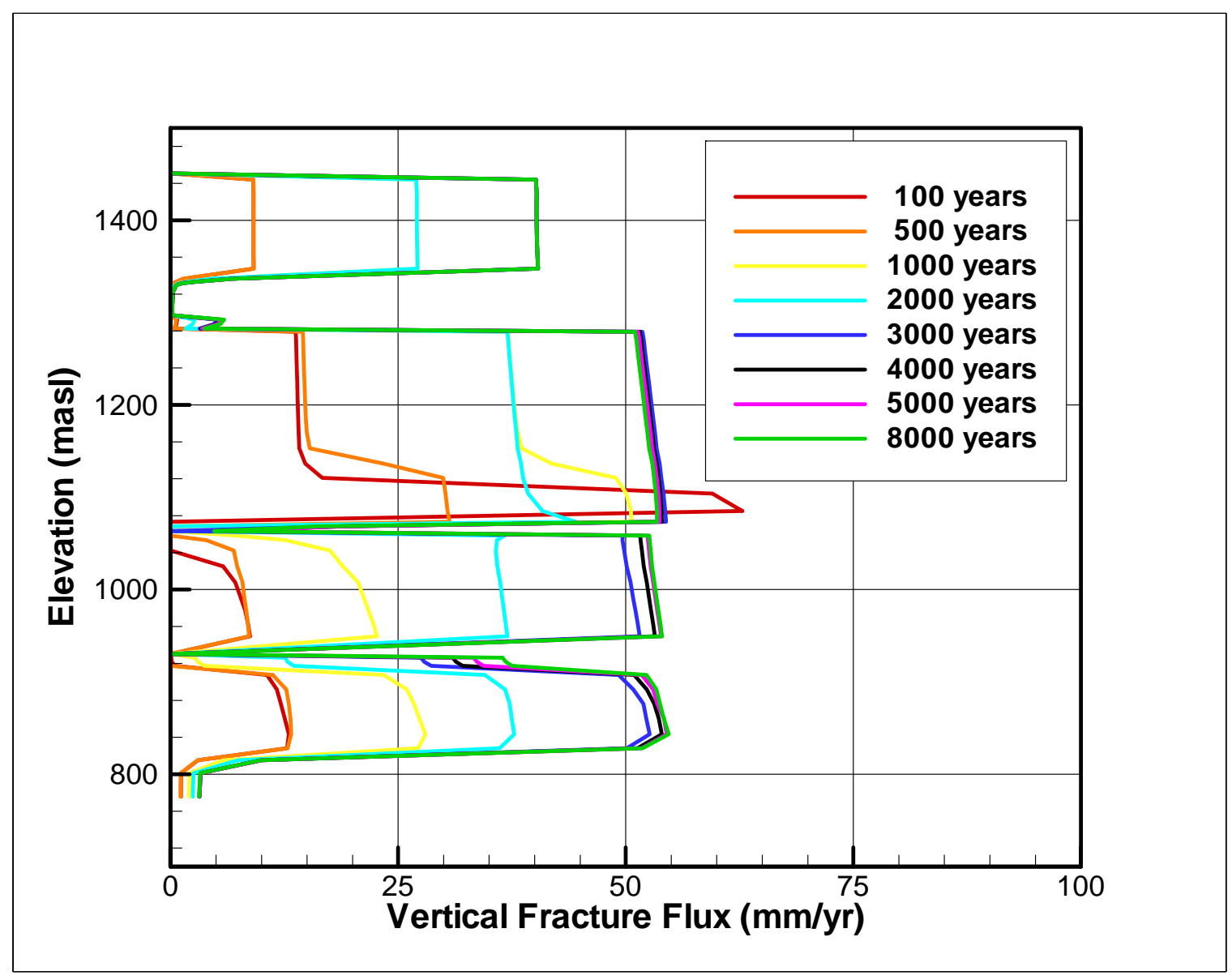

Figure 12c. Downward fracture fluxes along a vertical column from the ground surface to water table as predicted by the 2-D mountain-scale TH model without ventilation 


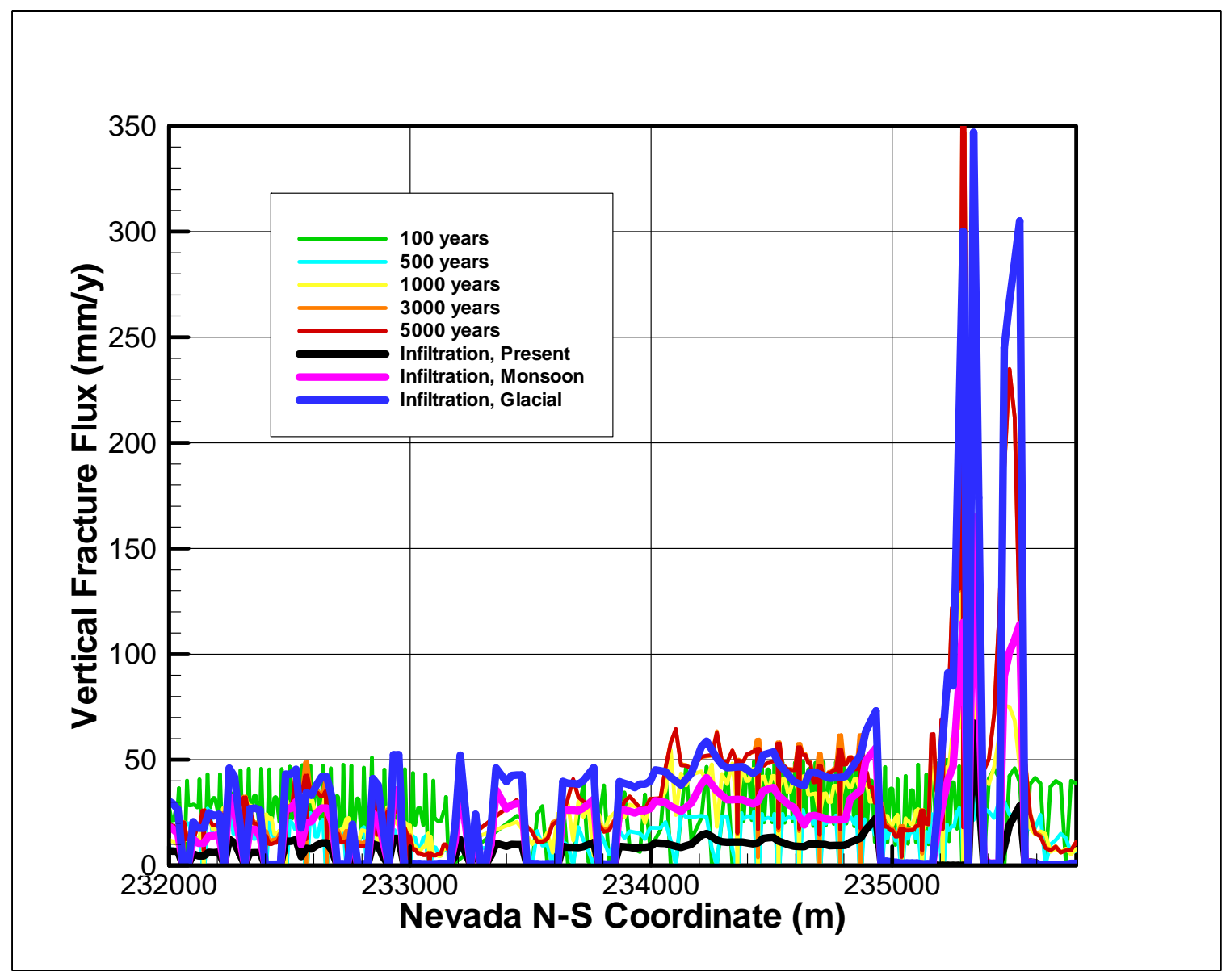

Figure 12d. Downward fracture fluxes just above the repository as predicted by the 2-D mountain-scale TH model without ventilation 


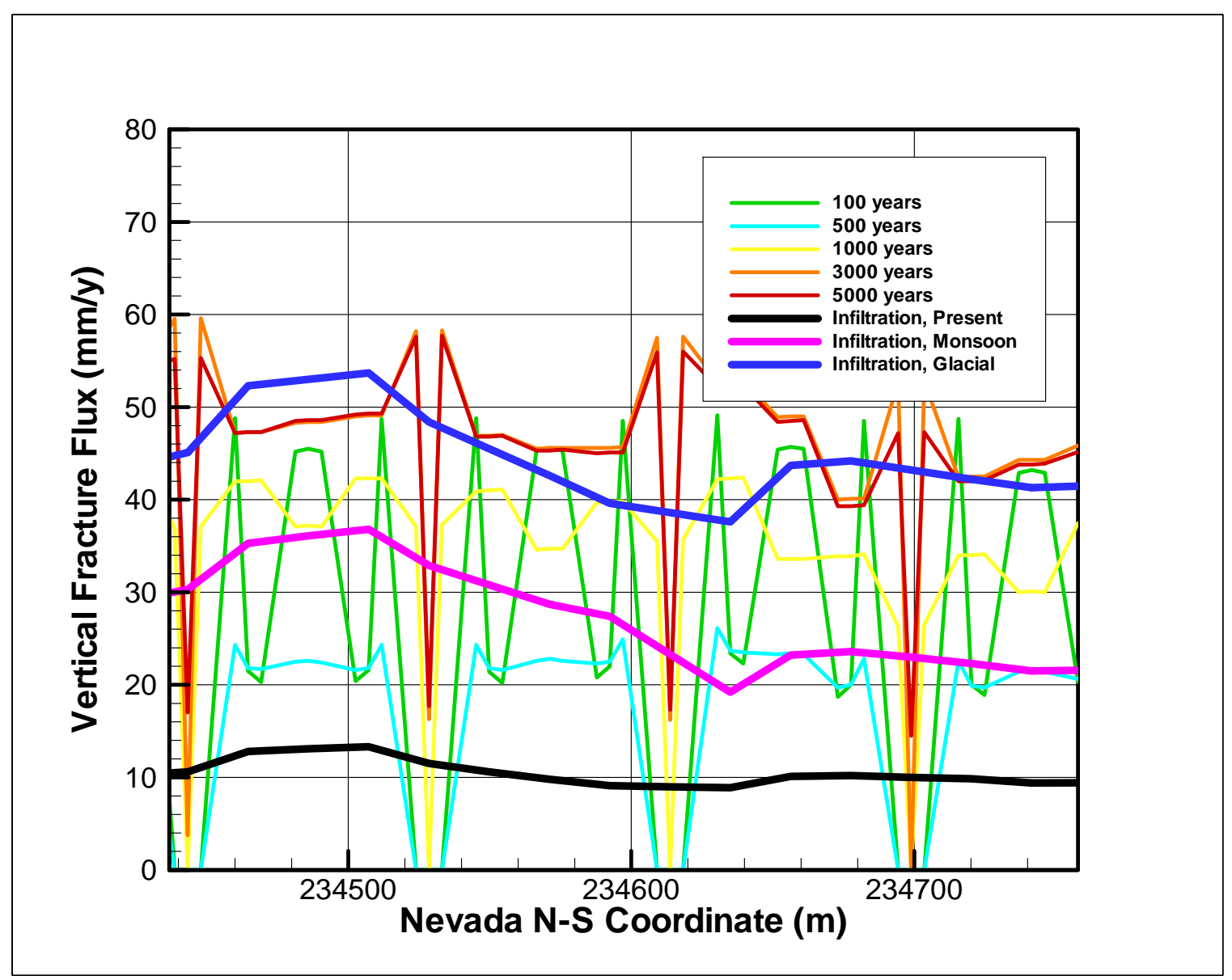

Figure 12e. Downward fracture fluxes over the pillar regions as predicted by the 2-D mountain-scale TH model without ventilation 


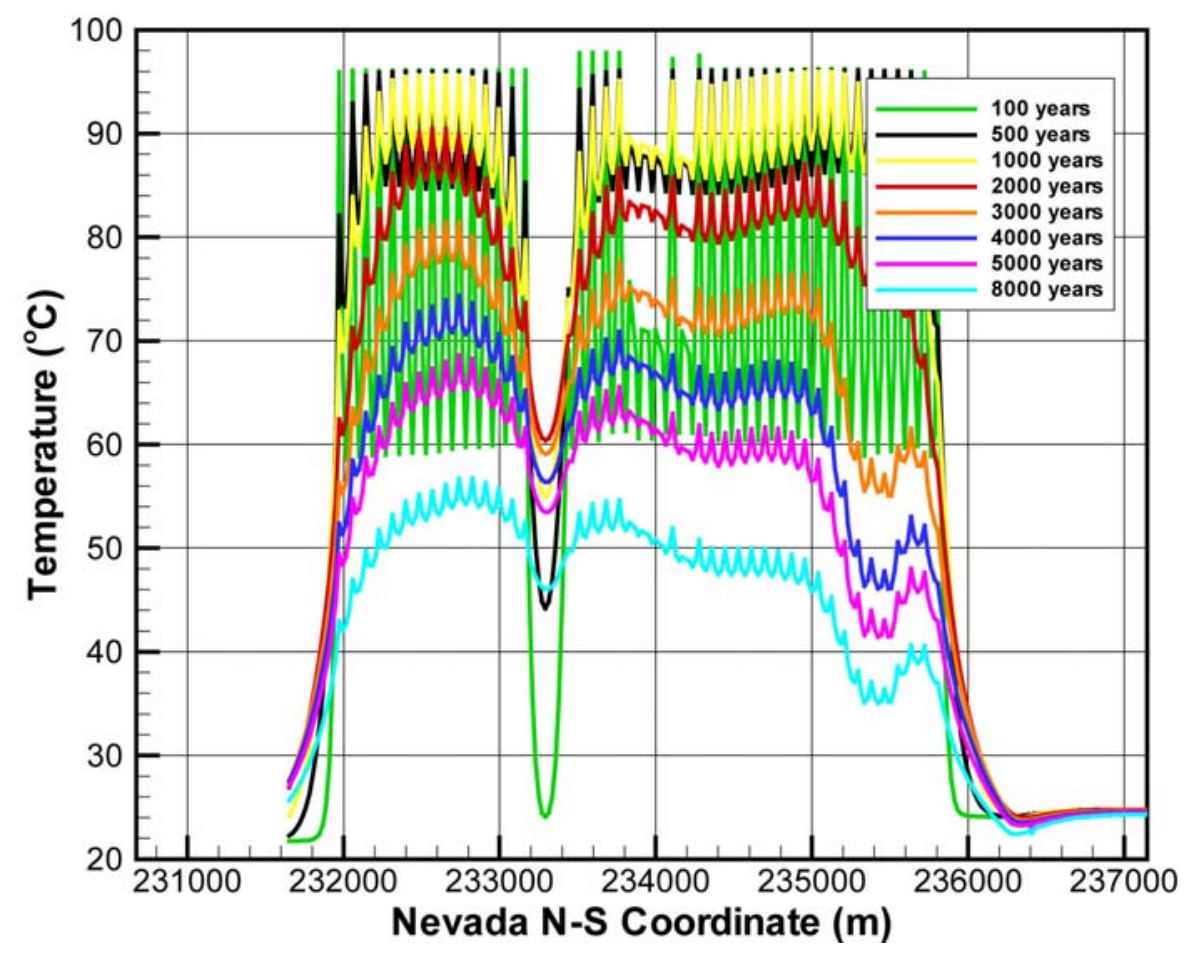

Figure 13a. Rock temperatures just above the repository as predicted by the 2-D mountain-scale TH model with $86.3 \%$ heat removal by ventialtion during the first 50 years after waste emplacement (Compare this figure with Figure 9a) 


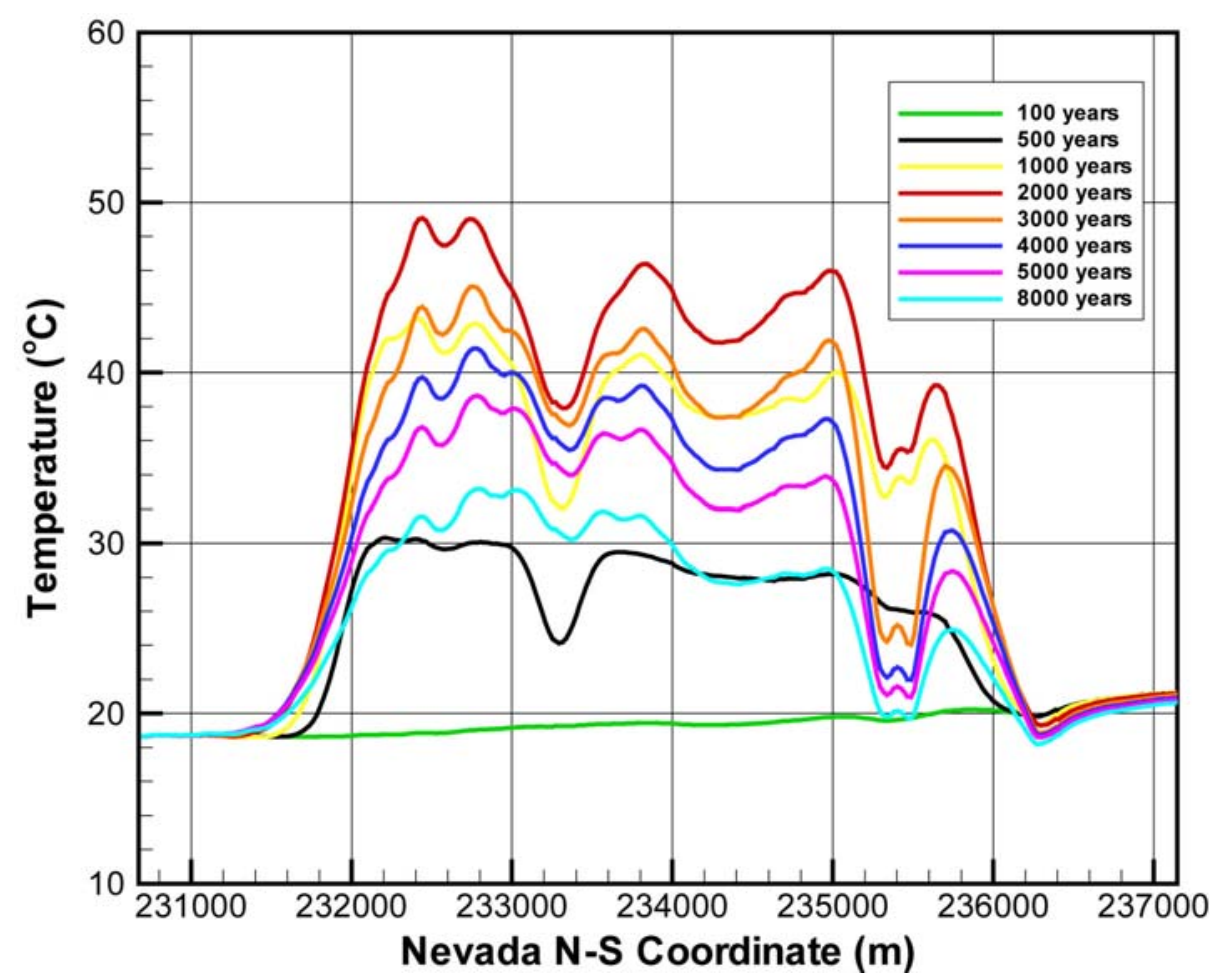

Figure 13b. Rock temperatures at the bottom of ptn as predicted by the 2-D mountainscale TH model with $86.3 \%$ heat removal by ventialtion during the first 50 years after waste emplacement (Compare this figure with Figure 9b) 


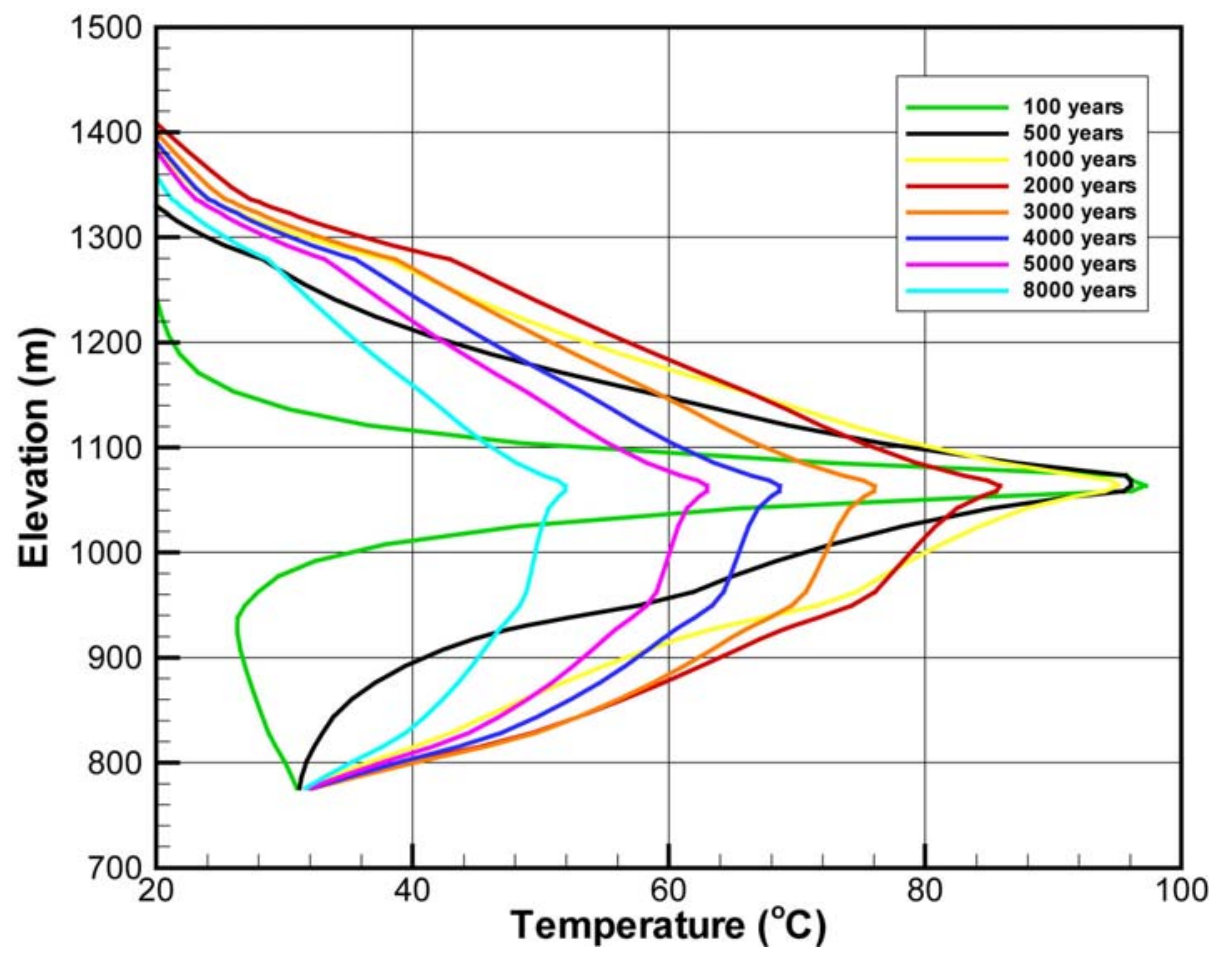

Figure 13c. Rock temperatures along a vertical column as predicted by the 2-D mountain-scale TH model with $86.3 \%$ heat removal by ventialtion during the first 50 years after waste emplacement (Compare this figure with Figure 9d) 


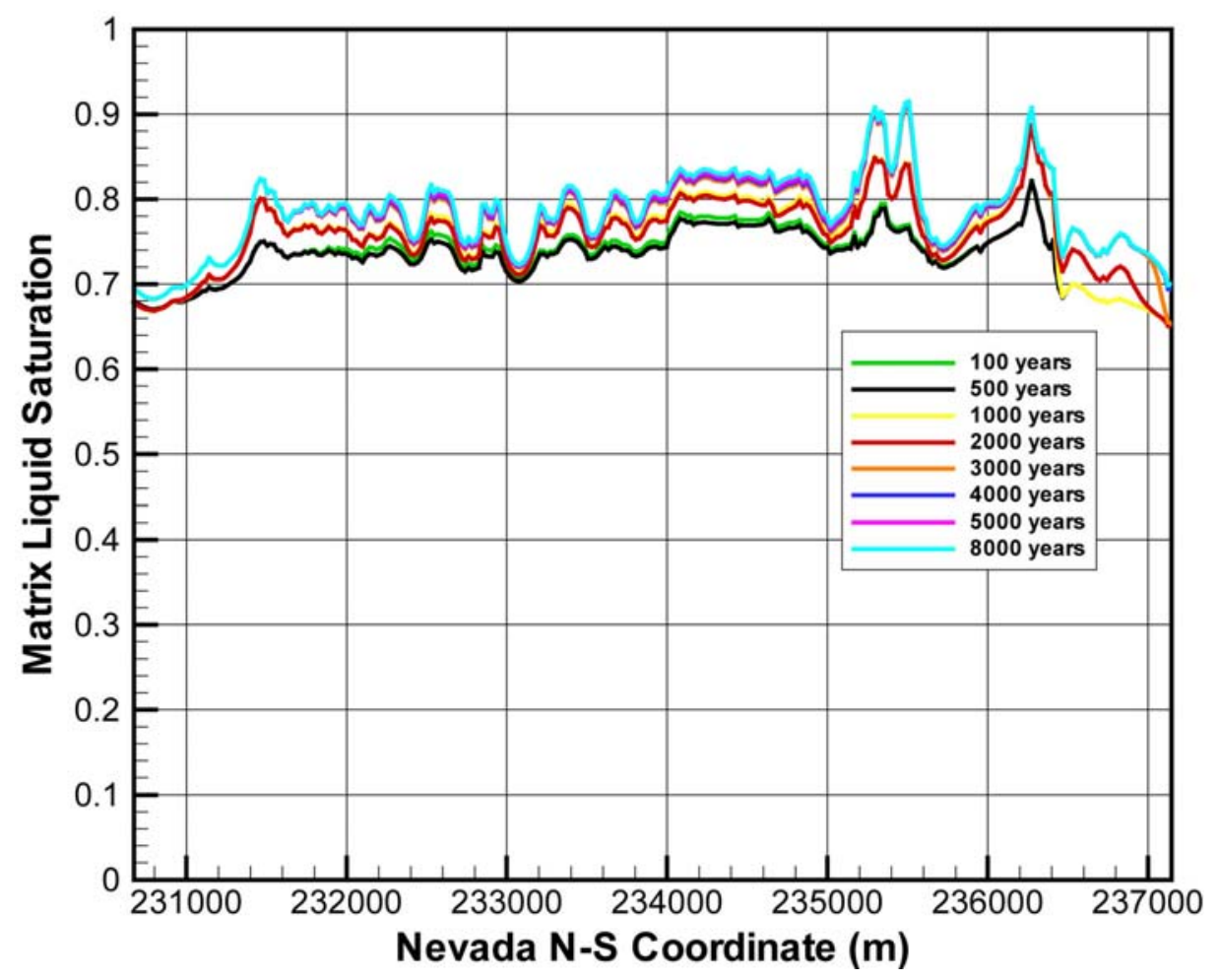

Figure 14. Matrix saturation at the bottom of ptn as predicted by the 2-D mountainscale THh model with $86.3 \%$ heat removal by ventialtion during the first 50 years after waste emplacement (Compare this figure with Figure 10b) 


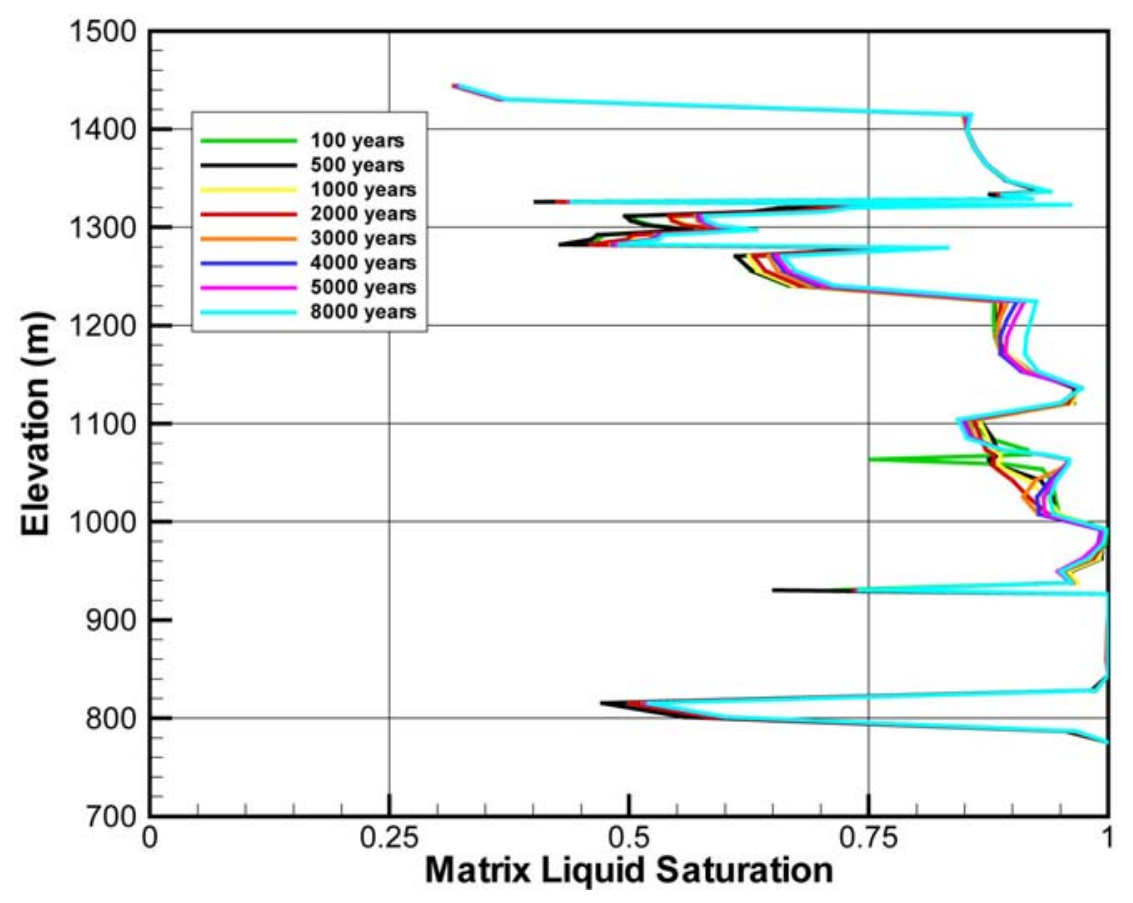

Figure 15. Matrix saturation along a vertical column as predicted by the 2-D mountain-scale TH model with $86.3 \%$ heat removal by ventialtion during the first 50 years after waste emplacement (Compare this figure with Figure 11d) 


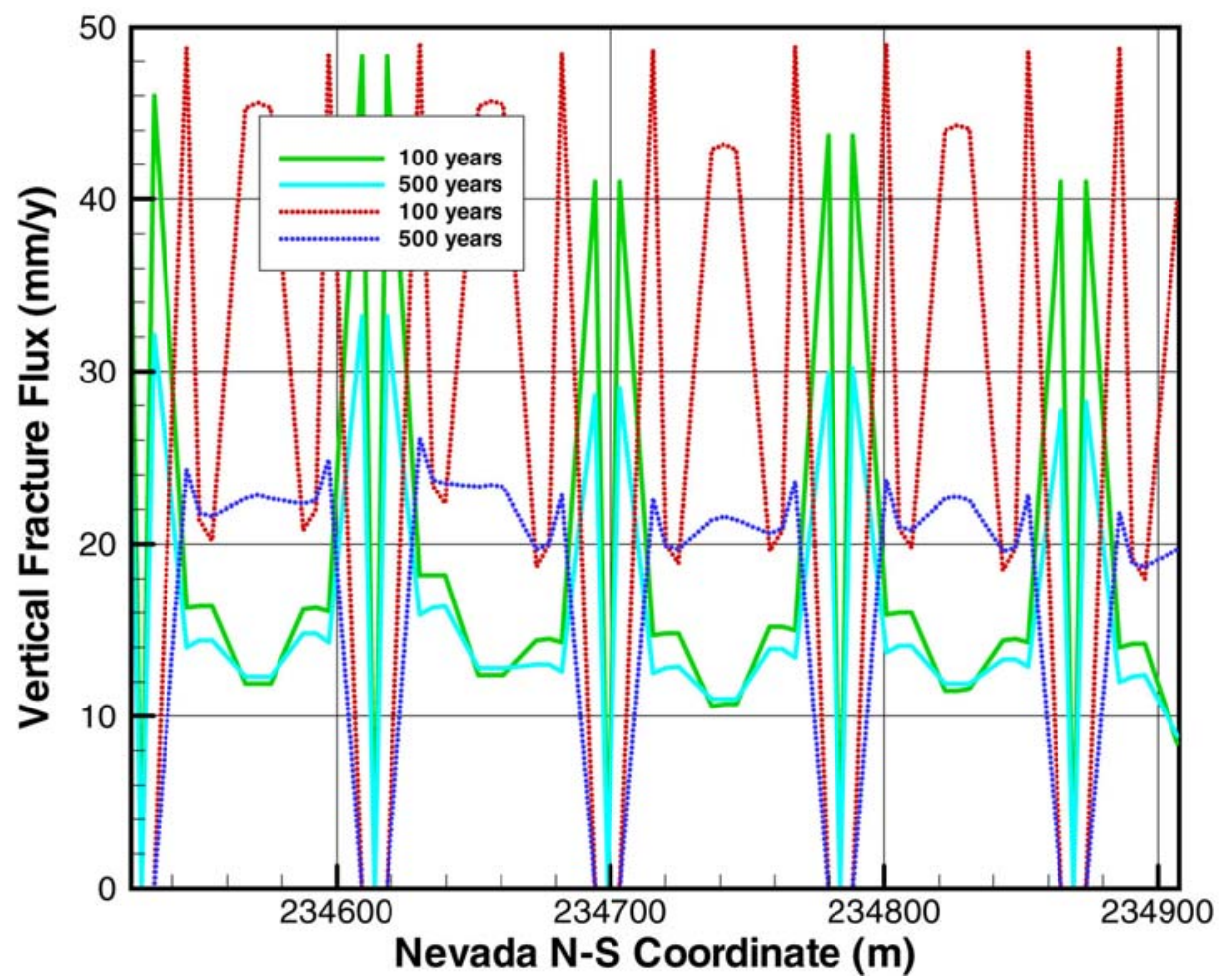

Figure 16. Vertical fracture liquid fluxes into the mid-pillar regions from top with (solid line) and without (dotted line) ventilation as predicted by the 2-D mountain-scale $\mathrm{TH}$ model 